\title{
Interactions Among Non-Coding RNAs in Diabetic Nephropathy
}

\author{
Tamil Selvi Loganathan ${ }^{1}$, Siti Aishah Sulaiman ${ }^{1 *}$, Nor Azian Abdul Murad ${ }^{1}$, \\ Shamsul Azhar Shah ${ }^{2}$, Abdul Halim Abdul Gafor ${ }^{3}$, Rahman Jamal ${ }^{1}$ \\ and Noraidatulakma Abdullah ${ }^{1}$ \\ 1 UKM Medical Molecular Biology Institute, Universiti Kebangsaan Malaysia, Kuala Lumpur, Malaysia, ${ }^{2}$ Department of \\ Community Health, UKM Medical Centre, Universiti Kebangsaan Malaysia, Kuala Lumpur, Malaysia, ${ }^{3}$ Nephrology Unit, \\ Faculty of Medicine, UKM Medical Centre, Universiti Kebangsaan Malaysia, Kuala Lumpur, Malaysia
}

OPEN ACCESS

Edited by:

Valeria Mas,

University of Tennessee Health Science Center (UTHSC), United States

Reviewed by: Edgar Jaimes,

Memorial Sloan Kettering Cancer Center, United States Xiaoxin Wang

Georgetown University Medical Center, United States

${ }^{*}$ Correspondence: Siti Aishah Sulaiman sitiaishahsulaiman@ukm.edu.my

Specialty section: This article was submitted to Renal Pharmacology, a section of the journal

Frontiers in Pharmacology

Received: 02 August 2019 Accepted: 10 February 2020 Published: 03 March 2020

Citation: Loganathan TS, Sulaiman SA, Abdul Murad NA, Shah SA, Abdul Gafor AH, Jamal $R$ and Abdullah N (2020) Interactions Among Non-Coding RNAs in Diabetic Nephropathy.

Front. Pharmacol. 11:191. doi: 10.3389/fphar.2020.00191
Diabetic Nephropathy (DN) is the most common cause of End-stage renal disease (ESRD). Although various treatments and diagnosis applications are available, DN remains a clinical and economic burden. Recent findings showed that noncoding RNAs (ncRNAs) play an important role in DN progression, potentially can be used as biomarkers and therapeutic targets. NcRNAs refers to the RNA species that do not encode for any protein, and the most known ncRNAs are the microRNAs (miRNAs), long noncoding RNAs (IncRNAs), and circular RNAs (circRNAs). Dysregulation of these ncRNAs was reported before in DN patients and animal models of DN. Importantly, there are some interactions between these ncRNAs to regulate the crucial steps in DN progression. Here, we aimed to discuss the reported ncRNAs in DN and their interactions with critical genes in DN progression. Elucidating these ncRNAs regulatory network will allow for a better understanding of the molecular mechanisms in DN and how they can act as new biomarkers for DN and also as the potential targets for treatment.

Keywords: IncRNA, miRNA, circRNA, diabetic nephropathy, biomarkers, kidney disease

\section{INTRODUCTION}

Diabetic nephropathy (DN) is the most common complication of both Type 1 and 2 diabetic patients and often results in End-stage renal disease (ESRD) (Gheith et al., 2016). Approximately about $20 \%-40 \%$ of diabetic patients will eventually develop DN and kidney disease, and this prevalence is depending on the population and ethnicity (Gheith et al., 2016). Despite advances in the diagnosis and treatment tools, DN remains a clinical burden. Early clinical diagnosis of DN is usually based on the presence of microalbuminuria $(30-300 \mathrm{mg} /$ day) or by the urinary albumin to creatinine ratio (> $30 \mathrm{mg} / \mathrm{g}$ of creatinine) (American Diabetes Association, 2019). However, in some patients with normoalbuminuria, a reduced glomerular filtration rate (GFR) was observed (American Diabetes Association, 2019), indicating that significant glomerular damage has already occurred before the albumin detection. Recent classification of DN stage progression showed that the clinical diagnosis of urinary albumin excretion (UAE) level is already in the third stage of the DN progression (Gheith et al., 2016). Therefore, identification and characterization of early biomarkers for DN become a priority. In this mini-review, we discussed the role of noncoding RNAs (ncRNAs) in DN progression and how they co-regulate each other and their target genes. 
Understanding of these ncRNAs regulatory networks in DN will allow for the discovery of new biomarkers and potential targets for treatment.

\section{NONCODING RNAS (NCRNAS)}

In a single cell, the complex molecular characteristics are due to the transcriptomic profile that includes the protein-coding RNAs and the non-coding RNAs (ncRNAs) expression. Our understanding of the central dogma of the biology is that the information from the DNA is transcribed into the RNA and then are translated to proteins though, recent evidence shown that our genome consists of more ncRNAs than the protein-coding RNAs, and these ncRNAs are functional (Bertone et al., 2004; Djebali et al., 2012). These observations open up the new paradigm in understanding gene expression and regulation, particularly the multiple and diverse layers of molecular management of a single gene (Cipriano and Ballarino, 2018; Sulaiman et al., 2019). To date, various classes of the ncRNAs have been discovered. Most of these ncRNAs are generally grouped based on their sizes, which is the small ncRNAs ( $<200$ nucleotides) that include the microRNAs (miRNAs) and some of the circular RNAs (circRNAs) (Alvarez and DiStefano, 2013; Bhat et al., 2016; He et al., 2017), and the large ncRNAs such as the long ncRNAs (lncRNAs) (Bhat et al., 2016).

\section{MicroRNAs (miRNAs)}

MiRNAs are the short single-stranded ncRNAs (size: 19-25 nucleotides), and their biogenesis and production have already extensively discussed before (Winter et al., 2009; Krol et al., 2010; $\mathrm{Ha}$ and Kim, 2014; O'Brien et al., 2018). The majority of the miRNAs are produced by RNA polymerases to generate the primiRNA transcripts from their genes in intronic clusters regions within the protein-coding genes (Rodriguez et al., 2004). Though some miRNAs do come from their genes, and some are within the lncRNAs (Rodriguez et al., 2004). Following that, the microprocessor complex (Drosha and DGCR8) cleaves the primiRNA to produce the distinctly hairpin structure of the precursor-miRNA (pre-miRNA) (Rodriguez et al., 2004). This pre-miRNA is processed further in the cytoplasm by RNase III endonuclease Dicer to remove the stem-loop structure to produce the mature miRNA duplex (Rodriguez et al., 2004). One of the mature miRNA duplex strands ( $5 p$ or $3 p$ strand) is incorporated into the functional miRNA-induced silencing complex (miRISC), which will bind to target messenger RNA (mRNAs) via complementary binding (Krol et al., 2010). A perfect complementary binding between the miRISC and the target mRNA will result in the mRNA degradation, whereas the incomplete complementary binding will lead to the translation repression (Rodriguez et al., 2004).

Studies have shown that miRNA-mediated gene regulation is a complex and dynamic process. A single miRNA could regulate many target genes at a time, and a single target mRNA could also be regulated by several miRNAs (Chowdhury et al., 2014; O'Brien et al., 2018), therefore implying the existence of the coordinated miRNA network in regulating the gene expression. Moreover, numerous evidence showing that the miRNA expression, regulatory action, and localization can change due to cellular environments (Ebert and Sharp, 2012; Kucherenko and Shcherbata, 2018). Serum starvation in multiple human cell lines has demonstrated that a significant decrease in intracellular miRNA levels with higher extracellular releases of these miRNAs either in vesicle form or as in circulating free miRNAs (Wang et al., 2010). Importantly, due to being released into extracellular fluids, these miRNAs may, therefore, can be used as biomarkers for disease.

\section{Long Noncoding RNA (IncRNAs)}

Long noncoding RNAs (lncRNAs) refer to a group of large ncRNAs (size: $>200$ nucleotides) that do not have any protein translation capacity (Quinn and Chang, 2015). Similar to mRNA production, lncRNAs are transcribed by the RNA polymerase II as the products of the alternative cleavage and splicing (Quinn and Chang, 2015; Yamamura et al., 2018). Though unlike mRNA, lncRNAs do not necessarily require polyadenylation for their functions, and in fact, some lncRNAs exist in both polyadenylated and non-polyadenylated forms (Derrien et al., 2012; Yamamura et al., 2017). The current classification of the lncRNAs is made based on their structure or size, localization, function, and interactions with other components (Dhanoa et al., 2018; Yao et al., 2019). Most of these lncRNAs come from the unconserved regions of the genome, such as the intergenic, exonic, or the distal protein-coding regions (Dhanoa et al., 2018; Yao et al., 2019). The secondary and tertiary structures of lncRNAs are quite conserved when compared to its primary structure (Quinn and Chang, 2015; Dhanoa et al., 2018). Due to their genomic origins, lncRNAs are, therefore, very difficult to characterize and highly diverse. In general, lncRNAs are grouped into five classes depending on their origins: 1) sense lncRNAs, 2) anti-sense lncRNAs, 3) bidirectional lncRNAs, 4) intronic lncRNAs, and 5) intergenic lncRNAs (Dhanoa et al., 2018).

In terms of their functions, lncRNAs can modulate gene expression at the transcriptional, post-transcriptional, and translational levels. Both cis- and trans-regulation of lncRNAs have been reported, in which the cis-regulatory lncRNAs exert their function on neighboring genes whereas the trans-regulatory lncRNAs exert their function to distant genes from their transcription sites (Yao et al., 2019). Generally, there are five modes of lncRNA functions. The first one is that lncRNA acts as the microRNA sponge or also known as the naturally competing endogenous RNAs (ceRNAs), in which the lncRNA can bind to a single microRNA with a complementary sequence and silences its-mediated actions towards the target mRNAs (Thomson and Dinger, 2016). This cross-talk and co-regulation of ceRNAs have garnered new interests to unravel the multilayered molecular regulation of a common target mRNA. The second function is that lncRNA could act as a signal due to the environmental stimulus and initiates or suppresses the transcription process by interacting with transcription factors or chromatin-modifying enzymes (Dhanoa et al., 2018; Yao et al., 2019). The third function is that lncRNA can act the 
molecular decoy by interacting with the target protein and prevents its action (Dhanoa et al., 2018; Yao et al., 2019). Fourth, the lncRNA acts as a guide for the localization of specific proteins or transcription factors and therefore activates or deactivates the genes. Lastly, the fifth function is that lncRNA acts as a scaffold platform or adaptor to allow for two or more proteins or RNA molecules to interact with each other and initiate the downstream effects (Dhanoa et al., 2018; Yao et al., 2019).

The majority of the lncRNAs are localized in the nucleus, in which they are enriched at the chromatin region to recruit the chromatin-modifying enzymes (Deniz and Erman, 2017; Yao et al., 2019). In some lncRNAs, a presence of a short sequence from Alu elements allows for the interactions with a nuclear matrix protein, HNRNPK, and consequently causing these lncRNAs pre-dominantly to localize in the nucleus (Lubelsky and Ulitsky, 2018). Whereas, some lncRNAs move into the cytoplasm, in which they usually regulate the mRNA translation and post-transcription modifications (Yao et al., 2019). LncRNA functions as the ceRNAs or molecular decoys are the classic example of mRNA translation regulation in the cytoplasm. Evidence of extracellular lncRNAs are limited, but several studies have managed to show that lncRNAs, similar to miRNAs, exist in the vesicle-form or circulating free in biological fluids (Kelemen et al., 2019). Importantly, most lncRNAs express at low levels usually, thus at a specific stage of the disease progression, their expressions arise (Bhat et al., 2016; He et al., 2017).

\section{Circular RNAs (circRNAs)}

A back-splicing event during the transcription process that ligates a splice donor site at the upstream to an acceptor sites at downstream of the RNA transcript, produces a covalently closed loop RNA product that does not contain either 5' to 3' polarity nor a poly-adenylated tail, and this is known as the circular RNA (circRNA) (Cao et al., 2018; Fang et al., 2018; Sulaiman et al., 2018; Hu et al., 2019). Due to its circular structure, circRNA is very stable and resistant to degradation by exoribonucleases (Liu et al., 2017; Cao et al., 2018). Similar to other ncRNAs, circRNAs do not encode for any protein products, and their biogenesis and production are wellregulated by cis-elements and trans-factors (Chen and Yang, 2015; Chen, 2016). Depending on their origins, the circRNAs are classified into four groups: 1) exonic circRNAs (ecircRNAs), 2) intronic circRNAs (ciRNAs), 3) exon-intron circRNAs (EIciRNAs), and 4) intergenic circRNAs (Memczak et al., 2013; Zhang et al., 2013; Li et al., 2015). As for their sizes, circRNAs sizes range from a few hundred to thousands of nucleotides (Chen and Yang, 2015).

CircRNAs are highly conserved across the eukaryotes (Conn et al., 2015), and like lncRNAs, their expressions are usually low but can be tissue- and developmental stage- or disease-specific (Abu and Jamal, 2016). Although circRNAs are known much earlier, its function and potential as biomarkers are not well understood. The most established function of circRNA is that
circRNAs can act as a sponge to miRNAs to regulate gene expression (Cao et al., 2018; Fang et al., 2018; Hu et al., 2019), and in some cases, with proteins (Du et al., 2016). In terms of the circRNAs localization, some exonic circRNAs are abundantly present in the cytoplasm (Jeck et al., 2013), but no other information is available for other groups of circRNAs. However, many studies showed that circRNAs do present in extracellular vesicles and in circulating free form (Hon et al., 2019). Identification of the circRNAs' role in the regulation of gene expression has expanded the understanding and knowledge about the complex interactions between these molecular regulators, which includes the miRNAs, lncRNAs, and circRNAs.

\section{DIABETIC NEPHROPATHY PROGRESSION}

Progression to $\mathrm{DN}$ in diabetic patients is a very complicated process and is due to multiple factors, and previous reviews have discussed this topic extensively (Remuzzi et al., 2005; Piero et al., 2010; Zhang et al., 2017). As a summary, in diabetic settings, metabolic dysregulation leads to the alteration of kidney hemodynamics, promotes glomerulosclerosis, tubulointerstitial inflammation, and fibrosis. Both hyperglycemia and renal hypertension are the most known mediators for DN progression (Tziomalos and Athyros, 2015). Hyperglycemia activates the polyol pathway, hexosamine pathway and protein kinase $\mathrm{C}(\mathrm{PKC})$, which results in the accumulation of intracellular advanced glycation end products (AGEs), glomerular hyperfiltration, and hypertension (Stephen et al., 2004; Shaheer et al., 2017; Lin et al., 2018). A key hallmark event during this stage is the activation of the renin-angiotensin system (RAS) following the changes in GFR (Chawla et al., 2010; Ahmad et al., 2019). Elevated GFR is observed with glomerular and renal hypertrophy, and these events cause an increase in intraglomerular pressure (Chawla et al., 2010). Activation of RAS cascade (from prerenin to Angiotensin-aldosterone) leads to glomerular afferent arteriole dilatation to increase renal blood flow as a feedback mechanism to maintain GFR. Though in diabetic individuals, hyperinsulinemia, and local Angiotensin II (AngII)-aldosterone also stimulates sodium reabsorption in the proximal tubule, mesangial cell constriction, and efferent arteriolar vasoconstriction (Chawla et al., 2010). Consequently, these events further increase intraglomerular pressure, tubulointerstitial inflammation, and worsen kidney damage (Chawla et al., 2010). A high level of AngII-aldosterone also stimulates reactive oxygen species (ROS) production, which further damage podocyte and tubular cells (Chawla et al., 2010). Increased glucose metabolism due to hyperglycemia also causes excessive production of ROS, which is highly potent and could damage the DNA and mitochondria (Stephen et al., 2004; Lin et al., 2018). The activation of the growth factors such as Transforming growth factor- $\beta$ (TGFB) and inflammatory cytokines via $\mathrm{PKC}$, mitogen-activated protein kinase (MAPK), and transcription factor nuclear factor- $\kappa \mathrm{B}(\mathrm{NF}-\kappa \mathrm{B})$ result in the downstream activation of tumor necrosis factor- $\alpha$ (TNFA) 
signaling and promotes cells repair and remodeling, which further aggravates the kidney lesion and fibrosis (Lin et al., 2018). Eventually, these uncontrolled and repeated kidney damages will lead to total kidney failure.

\section{NONCODING RNAS (NCRNAS) IN DN}

\section{Renal Hypertrophy and ECM Accumulation}

The presence of TGFB in the kidney usually indicates a progression towards the renal hypertrophy and extracellular matrix (ECM) accumulation, together with evidence of RAS activation during renal hypertension Recent findings in DN patients and animal models have revealed that some of these ncRNAs regulate these early events in DN development (Bhat et al., 2016; Leti and DiStefano, 2017). Characterization of these ncRNAs in DN progression will allow for the discovery of early biomarkers for disease diagnosis and potential therapeutic targets, as these ncRNAs' expressions may reflect the early disease development (Alvarez and DiStefano, 2013; Bhat et al., 2016; He et al., 2017).

\section{MicroRNAs in Renal Hypertrophy and ECM Accumulation}

MicroRNAs (miRNAs) are the most studied ncRNAs in renalassociated complications (Simpson et al., 2016) (Table 1). Recent systematic review and meta-analysis in 12 of previous DN human studies (Wang et al., 2019b), showed that 15 miRNAs were upregulated in DN, including miRNA-21, miRNA-181b, and miRNA-215. Whereas, seven miRNAs were downregulated in DN, including miRNA-26a, miRNA-126, miRNA-574-3p, miR-155, and miR-192 (Wang et al., 2019b). Importantly, the UAE rates correlated with these six miRNAs expressions (miR133b, miR-342, miR-30, miR-192, miR-194, and miR-215), urinary albumin-creatinine ratio associated with five miRNAs expressions (miR-192, miR-217, miR-15b, miR-34a, and miR636), and the GFR correlated with twelve miRNAs expressions (Eissa et al., 2016b; Wang et al., 2019b).

Among these reported miRNAs, some are shown to regulate RAS and renal hypertension (Hagiwara et al., 2013) (Table 1). For example, investigation in the human kidney cell line showed that miR-663 directly regulates the expression of renin $(R E N)$ and apolipoprotein $\mathrm{E}(A P O E)$ genes, and miR-181a directly regulates the expression of $R E N$ and apoptosis-inducing factor, mitochondrion-associated-1 (AIFM1) genes (Marques et al., 2011). Inhibition of these miRNAs expression will increase their target genes expressions like the renin and, thus, induce the RAS cascade-production of angiotensin I/II and aldosterone, which is a significant dysregulation event in the early DN progression (Marques et al., 2011). Therefore, the reduction of both miRNAs' expression (miR-181a and miR-663) in the patients can be used as the early biomarkers of $\mathrm{DN}$, since their reduced expression may reflect the start of the RAS activation. Moreover, both miR-181a and miR-663 expressions were reduced in hypertensive renal tissue (Marques et al., 2011), and serum expression of miR-181a can be a biomarker for the renal
miR-181a (Marques et al., 2015) thus, confirming that these miRNAs can serve as biomarkers for early dysregulation of RAS in DN patients. Besides that, Ang II itself can increase five downstream miRNAs expressions, including miR-29b, miR129-3p, miR-132, miR-132-5p, and miR-212, as reported in a human kidney cell line study with the overexpression of Angiotensin II receptor type 1 (AT1R) (Jeppesen et al., 2011). Though, only some of these miRNAs are involved in DN, particularly the miR-29b and its role in kidney fibrosis and cell death (Sun et al., 2018a). Understanding the roles of miRNAs in RAS activation is important, as RAS blocker therapy or treatment is currently one of the main treatments for DN patients (Jeppesen et al., 2011).

Another early dysregulated miRNAs in DN progression is the miR-192 (Kato et al., 2009; Krupa et al., 2010; Jia et al., 2016; Andrea et al., 2018). MiR-192 is the most abundant miRNA in the kidney, in which its high expression protects the kidney function (Krupa et al., 2010). In DN patients and mice model, miR-192 expression was reduced as the DN progresses (Kato et al., 2009; Krupa et al., 2010; Jia et al., 2016). This reduction of miR-192 expression removed the suppression of the E box repressors, Zeb1, and Zeb2 expressions, which are the inducers of the TGFB pathway, and further promoted TGFB-induced downstream activation of other miRNAs to promote renal hypertrophy and ECM accumulation (Kato et al., 2007). One example of the TGFBdownstream miRNAs is the miR-21, which is the most wellknown miRNA in DN and its expression was upregulated in both human DN and mice models (Zhang et al., 2009; Sayilar et al., 2016; Chen et al., 2018; Wang et al., 2019a). MiR-21 negatively regulates the expression of Phosphatase and tensin homolog (PTEN) and matrix metalloproteinases (Chau et al., 2012). Hyperglycemia condition upregulates miR-21 expression in the plasma and urine samples (Sayilar et al., 2016). In a study of DN patients, miR-21 expression was elevated in the kidney biopsy and correlated with the podocyte cell damage, together with a reduced metalloproteinase inhibitor-3 (TIMP3) expression (Chen et al., 2018). TIMP3 is an important regulator of a healthy kidney, and the reduction of its expression increases the podocyte cell death (Chen et al., 2018). Another target of miR-21 is the forkhead box O1 (Foxo1), which was down-regulated in $\mathrm{DN}$-induced by hyperglycemia condition (Wang et al., 2019a). Treatment of a currently clinical-trialed DN drug, Atrasentan (an endothelin-1 receptor antagonist) reduced miR-21 expression, restored the Foxol expression, and thus promoted renal autophagy (Wang et al., 2019a). Therefore, following TGFB response, majority of these downstream network of miRNA activates the PI3K/AKT/mTOR pathway, by targeting the PTEN (miR-216a, miR-217, miR-21, miR-22, miR-25, and miR214) (Kato et al., 2009; Denby et al., 2011; Li et al., 2017a; Zhang et al., 2018), collagen type I alphal (COLIA1), Collagen IV (COL4), and Fibronectin (FN) (miR-130b) (Ma et al., 2019), PI3K inhibitor (Fog2) (miR-200 family) (Park et al., 2013), Tyrosine 3monooxygenase (Ywhab) (miR-451) (Zhang et al., 2012), DEP domain-containing mTOR-interacting protein (Deptor) (miR181a) (Maity et al., 2018), Protein canopy homolog-1 (Cnpy1) (miR-370) (Yu et al., 2019), high-mobility group AT-hook-2, Hmga2 (let-7a-5p) (Wang et al., 2019c), Insulin receptor 
TABLE 1 | List of the reported noncoding RNAs in Diabetic Nephropathy.

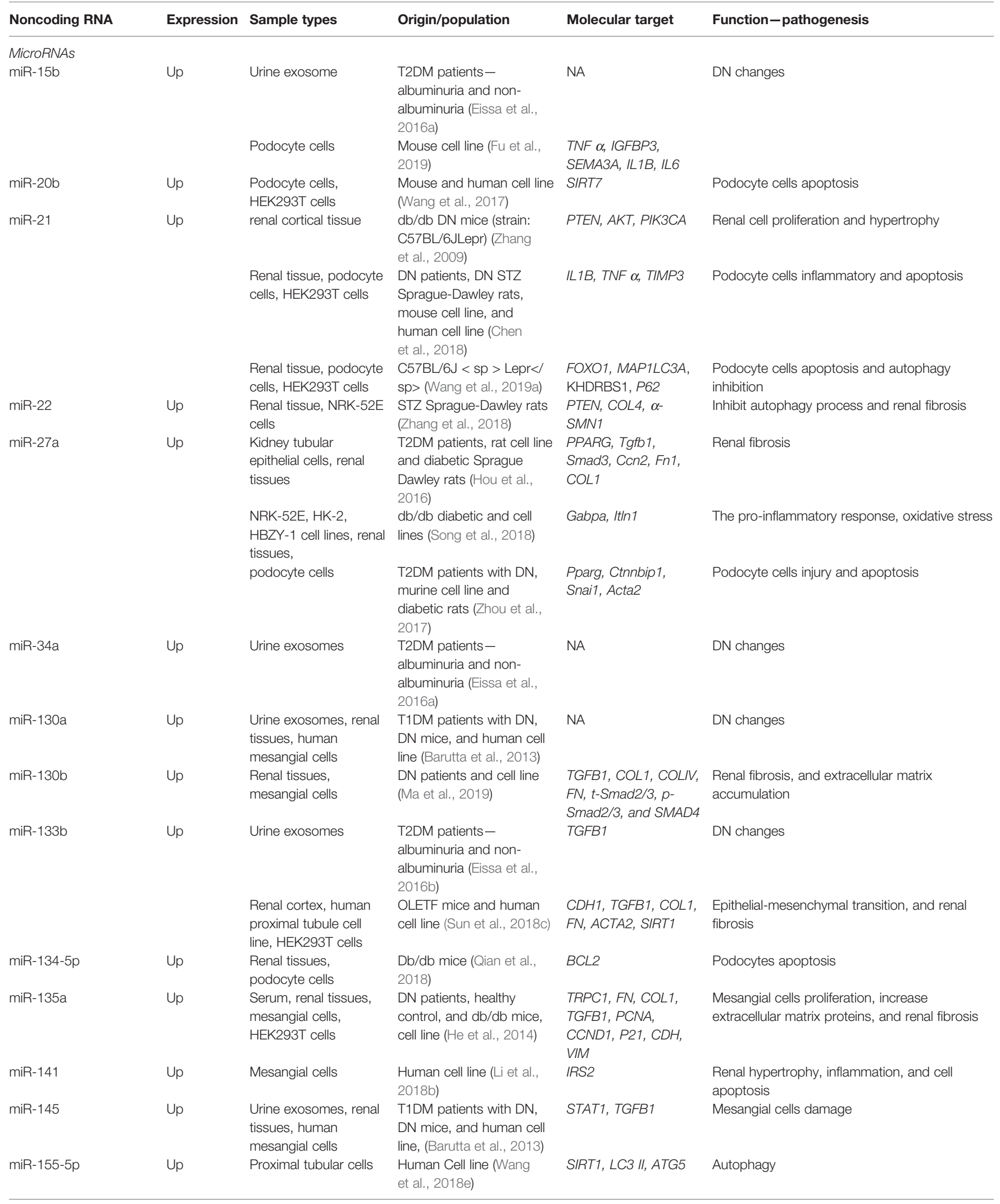


TABLE 1 | Continued

\begin{tabular}{|c|c|c|c|c|c|}
\hline Noncoding RNA & Expression & Sample types & Origin/population & Molecular target & Function-pathogenesis \\
\hline miR-181a & Up & Plasma & $\begin{array}{l}\text { DN patients (Bijkerk et al., } \\
\text { 2015) }\end{array}$ & NA & Microvascular damage \\
\hline miR-181b & Up & $\begin{array}{l}\text { Glomerular mesangial } \\
\text { cells, renal biopsy }\end{array}$ & $\begin{array}{l}\text { DN patients (Zhu et al., } \\
\text { 2019) }\end{array}$ & TIMP3 & Mesangial cells apoptosis \\
\hline miR-182-5p & Up & $\begin{array}{l}\text { Renal biopsy, } \\
\text { podocyte cells }\end{array}$ & $\begin{array}{l}\text { DN patients and cell line } \\
\text { (Ming et al., 2019) }\end{array}$ & $\begin{array}{l}\text { CD2AP, FOXO1, } \\
\text { BCL2 }\end{array}$ & Podocyte cells injury and apoptosis \\
\hline \multirow[t]{3}{*}{ miR-192 } & Up & $\begin{array}{l}\text { Renal cortical tissues, } \\
\text { mesangial cells }\end{array}$ & $\begin{array}{l}\text { db/db mice (Kato et al., } \\
\text { 2009) }\end{array}$ & $\begin{array}{l}\text { Tgfb 1, Akt, Pten, E } \\
\text { box }\end{array}$ & $\begin{array}{l}\text { Glomerular hypertrophy, mesangial cells } \\
\text { expansion, Renal fibrosis, extracellular matrix } \\
\text { accumulation, and tubular damage Glomerular } \\
\text { hypertrophy and mesangial cells expansion }\end{array}$ \\
\hline & & $\begin{array}{l}\text { Urine extracellular } \\
\text { vesicles, renal tubular } \\
\text { epithelial cells, } \\
\text { mesangial cells, }\end{array}$ & $\begin{array}{l}\text { Albuminuria patients and } \\
\text { human cell line (Jia et al., } \\
\text { 2016) }\end{array}$ & TGFB1 & Tubular and mesangial cells damage \\
\hline & & Renal biopsy & $\begin{array}{l}\text { DN patients (Krupa et al., } \\
\text { 2010) }\end{array}$ & TGFB1, ZEB1, CDH1 & Tubulointerstitial fibrosis \\
\hline miR-194 & Up & $\begin{array}{l}\text { Urine extracellular } \\
\text { vesicles, human renal } \\
\text { tubular epithelial cells, } \\
\text { human mesangial cells }\end{array}$ & $\begin{array}{l}\text { DN patients with T2DM } \\
\text { and human cell line (Jia et } \\
\text { al., 2016) }\end{array}$ & $A K T, T R A F 6$ & Tubular and mesangial cells damage \\
\hline $\operatorname{miR}-195$ & Up & Plasma and urine & $\begin{array}{l}\text { CKD patients (Sayilar et } \\
\text { al., 2016) }\end{array}$ & NA & DN changes \\
\hline miR-199b & Up & $\begin{array}{l}\text { Renal cortex, human } \\
\text { proximal tubular } \\
\text { epithelial cells }\end{array}$ & $\begin{array}{l}\text { OLETF mice and human } \\
\text { cell line (Sun et al., 2018a) }\end{array}$ & $\begin{array}{l}\text { CDH1, TGFB1, COL1, } \\
\text { FN, ACTA2, SIRT1 }\end{array}$ & $\begin{array}{l}\text { Epithelial-mesenchymal transition, and renal } \\
\text { fibrosis }\end{array}$ \\
\hline miR-200 & Up & $\begin{array}{l}\text { Renal cortex tissues, } \\
\text { mesangial cells }\end{array}$ & $\begin{array}{l}\text { db/db mice (Park et al., } \\
\text { 2013) }\end{array}$ & Fog2, Pi3k, Tgfb1 & Glomerular mesangial hypertrophy \\
\hline $\operatorname{miR}-212$ & Up & Renal, plasma & $\begin{array}{l}\text { Sprague-Dawley rats } \\
\text { (Eskildsen et al., 2013) }\end{array}$ & Angiotensin, MAPK3 & Hypertension in renal \\
\hline miR-215 & Up & $\begin{array}{l}\text { Urine extracellular } \\
\text { vesicles, renal tubular } \\
\text { epithelial cells, } \\
\text { mesangial cells }\end{array}$ & $\begin{array}{l}\text { Albuminuria patients and } \\
\text { human cell line (Jia et al., } \\
\text { 2016) }\end{array}$ & TGFB1 & Tubular and mesangial cells damage \\
\hline miR-216a & Up & $\begin{array}{l}\text { Renal cortex tissues, } \\
\text { mesangial cells }\end{array}$ & $\begin{array}{l}\text { db/db mice (Kato et al., } \\
\text { 2009) }\end{array}$ & Tgfb, Akt, Pten, Zeb1 & $\begin{array}{l}\text { Glomerular hypertrophy and mesangial cells } \\
\text { expansion }\end{array}$ \\
\hline $\operatorname{miR}-217$ & Up & $\begin{array}{l}\text { Renal cortex tissues, } \\
\text { mesangial cells }\end{array}$ & $\begin{array}{l}\text { db/db mice (Kato et al., } \\
\text { 2009) }\end{array}$ & Tgfb, Akt, Pten, Zeb1 & $\begin{array}{l}\text { Glomerular hypertrophy and mesangial cells } \\
\text { expansion }\end{array}$ \\
\hline miR-320 & Up & $\begin{array}{l}\text { Renal cortex tissues, } \\
\text { podocyte cells }\end{array}$ & $\begin{array}{l}\mathrm{Db} / \mathrm{db} \text { mice (He et al., } \\
\text { 2019) }\end{array}$ & Mafb & Podocyte cells injury and apoptosis \\
\hline miR-324-3p & Up & $\begin{array}{l}\text { Glomerular cells, } \\
\text { tubular cells }\end{array}$ & $\begin{array}{l}\text { Munich Wistar Fromter } \\
\text { mice (Macconi et al., } \\
\text { 2012) }\end{array}$ & $\begin{array}{l}\text { Angiotensin, Ac- } \\
\text { SDKP, Prep }\end{array}$ & Renal fibrosis \\
\hline miR-337 & Up & $\begin{array}{l}\text { Renal tissues, } \\
\text { mesangial cells }\end{array}$ & $\begin{array}{l}\text { DN mice and human cell } \\
\text { line (Wang et al., 2008) }\end{array}$ & TGFB & $\begin{array}{l}\text { Mesangial cells expansion, and renal toxicity } \\
\text { and fibrosis }\end{array}$ \\
\hline $\operatorname{miR}-342$ & Up & Urine exosomes & $\begin{array}{l}\text { T2DM patients- } \\
\text { albuminuria and non- } \\
\text { albuminuria (Eissa et al., } \\
\text { 2016b) }\end{array}$ & TGFB1 & DN changes \\
\hline miR-370 & Up & $\begin{array}{l}\text { Renal tissues, } \\
\text { mesangial cells }\end{array}$ & DN mice (Yu et al., 2019) & Cnpy1 & $\begin{array}{l}\text { Mesangial cells proliferation and extracellular } \\
\text { matrix accumulation }\end{array}$ \\
\hline \multirow[t]{2}{*}{$\operatorname{miR}-377$} & Up & $\begin{array}{l}\text { Renal tissues, } \\
\text { mesangial cells }\end{array}$ & $\begin{array}{l}\text { DN mice and human cell } \\
\text { line (Wang et al., 2008) }\end{array}$ & $\begin{array}{l}\text { FN, PAK1, SOD1, } \\
\text { SOD2, TGFB }\end{array}$ & Renal toxicity and fibrosis \\
\hline & & $\begin{array}{l}\text { Renal cortex, } \\
\text { mesangial cells }\end{array}$ & $\begin{array}{l}\text { T2DM db/db mice and } \\
\text { mice cell line (Kato et al., } \\
\text { 2016) }\end{array}$ & $\begin{array}{l}\text { Tgfb 1, Akt, Erk, Chop, } \\
\text { Edem3 }\end{array}$ & $\begin{array}{l}\text { Endoplasmic reticulum stress, and glomerular } \\
\text { extracellular matrix and hypertrophy }\end{array}$ \\
\hline miR-379 & Up & $\begin{array}{l}\text { Renal tissues, } \\
\text { mesangial cells }\end{array}$ & $\begin{array}{l}\mathrm{db} / \mathrm{db} \text { mice and mouse } \\
\text { cell line (Kato et al., 2016) }\end{array}$ & $\begin{array}{l}\text { Tgfb 1, Akt, Erk, Chop, } \\
\text { Edem3 }\end{array}$ & $\begin{array}{l}\text { Renal toxicity and fibrosis, endoplasmic } \\
\text { reticulum stress, extracellular matrix } \\
\text { accumulation, and podocyte cells injury }\end{array}$ \\
\hline miR-382 & Up & $\begin{array}{l}\text { Renal tissue, } \\
\text { mesangial cells }\end{array}$ & $\begin{array}{l}\text { STZ mice (Wang et al., } \\
\text { 2018c) }\end{array}$ & Foxo1 & $\begin{array}{l}\text { Renal hypertrophy and extracellular matrix } \\
\text { accumulation }\end{array}$ \\
\hline miR-4449 & Up & Serum exosomes & $\begin{array}{l}\text { DN patients (Kim et al., } \\
\text { 2019) }\end{array}$ & NA & Angiogenesis \\
\hline
\end{tabular}


TABLE 1 | Continued

\begin{tabular}{|c|c|c|c|c|c|}
\hline Noncoding RNA & Expression & Sample types & Origin/population & Molecular target & Function-pathogenesis \\
\hline \multirow[t]{2}{*}{$\operatorname{miR}-451$} & Up & Plasma and urine & $\begin{array}{l}\text { CKD patients (Sayilar } \\
\text { et al., 2016) }\end{array}$ & NA & DN changes \\
\hline & & $\begin{array}{l}\text { Renal tissues, primary } \\
\text { mouse mesangial cells }\end{array}$ & $\begin{array}{l}\text { DN mice, and cell line } \\
\text { (Zhang et al., 2012), }\end{array}$ & Ywhab, P38 Mapk & Renal fibrosis and glomerular cells proliferation \\
\hline $\operatorname{miR}-494$ & Up & $\begin{array}{l}\text { Renal tissues, } \\
\text { mesangial cells }\end{array}$ & $\begin{array}{l}\text { db/db mice and cell line } \\
\text { (Kato et al., 2016) }\end{array}$ & Tgfb 1, Akt, Erk, Chop & Renal toxicity and fibrosis \\
\hline \multirow[t]{2}{*}{ miR-495 } & Up & $\begin{array}{l}\text { Renal tissues, } \\
\text { mesangial cells }\end{array}$ & $\begin{array}{l}\text { db/db mice and cell line } \\
\text { (Kato et al., 2016) }\end{array}$ & Tgfb 1, Akt, Erk, Chop & Renal toxicity and fibrosis \\
\hline & & Urine & $\begin{array}{l}\text { T1DM patients with DN } \\
\text { (Christos et al., 2015) }\end{array}$ & NA & DN changes \\
\hline miR-503 & Up & $\begin{array}{l}\text { Renal tissues, } \\
\text { podocyte cells }\end{array}$ & $\begin{array}{l}\text { STZ mice (Zha et al., } \\
\text { 2019) }\end{array}$ & E2f3 & Podocyte cells injury and apoptosis \\
\hline miR-636 & Up & Urine exosome & $\begin{array}{l}\text { T2DM patients- } \\
\text { albuminuria and non- } \\
\text { albuminuria (Eissa et al., } \\
\text { 2016a) }\end{array}$ & NA & DN changes \\
\hline $\operatorname{miR}-770-5 p$ & Up & Podocyte cells & $\begin{array}{l}\text { Mice cell line (Zhang et al., } \\
\text { 2019) }\end{array}$ & Triap1 & Podocyte cells apoptosis and cells death \\
\hline miR-181a & Down & Renal tissue & $\begin{array}{l}\text { Hypertensive and } \\
\text { normotensive patients } \\
\text { (Marques et al., 2011) }\end{array}$ & AIFM1, APOE, RENIN & Hypertension in renal \\
\hline \multirow[t]{3}{*}{ miR-25 } & Down & $\begin{array}{l}\text { Serum, renal tissue, } \\
\text { and HK-2 cells }\end{array}$ & $\begin{array}{l}\text { DN patients and human } \\
\text { cell line (Li et al., 2017a) }\end{array}$ & PTEN, AKT & $\begin{array}{l}\text { Renal tubular epithelial cell injury and apoptosis, } \\
\text { mesangial cells injury, and glomerular } \\
\text { hypertrophy }\end{array}$ \\
\hline & & Renal tissue & $\begin{array}{l}\text { STZ Sprague-Dawley rats } \\
\text { (Fu et al., 2010) }\end{array}$ & NOX4 & \\
\hline & & $\begin{array}{l}\text { Glomeruli, mesangial } \\
\text { cell }\end{array}$ & $\begin{array}{l}\text { STZ mice and cell line (Oh } \\
\text { et al., 2016) }\end{array}$ & p-MeCP2, Hipk2, Tgfb & Oxidative stress \\
\hline miR-26a & Down & $\begin{array}{l}\text { Renal biopsy, STZ } \\
\text { mice, and human } \\
\text { podocyte cells }\end{array}$ & $\begin{array}{l}\text { DN patients, STZ mice, } \\
\text { and human cell (Koga } \\
\text { et al., 2015) }\end{array}$ & $\begin{array}{l}\text { TGFB, CTGF, SMAD, } \\
\text { CTDSP2, CTDSPL }\end{array}$ & Extracellular matrix accumulation \\
\hline \multirow[t]{2}{*}{ miR-29a } & Down & $\begin{array}{l}\text { Glomeruli, podocyte } \\
\text { cells }\end{array}$ & STZ mice (Lin et al., 2014) & Nephrin & Podocyte cell apoptosis \\
\hline & & Mesangial cells & $\begin{array}{l}\text { Mice and cell line (Tung } \\
\text { et al., 2019) }\end{array}$ & Cb1r, Pparg & Renal hypertrophy \\
\hline miR-30 & Down & Urine exosomes & $\begin{array}{l}\text { T2DM patients - } \\
\text { albuminuria and non- } \\
\text { albuminuria (Eissa et al., } \\
\text { 2016b) }\end{array}$ & NA & DN changes \\
\hline \multirow[t]{3}{*}{ miR-93 } & Down & $\begin{array}{l}\text { Renal microvascular } \\
\text { endothelial cells, } \\
\text { podocyte cells }\end{array}$ & $\begin{array}{l}\text { Mice cell line and diabetes } \\
\text { db/db mice (Long et al., } \\
\text { 2010) }\end{array}$ & Vegfa, Mcm7 & Podocyte cells damage \\
\hline & & $\begin{array}{l}\text { Podocyte cells, renal } \\
\text { tissues }\end{array}$ & $\begin{array}{l}\text { Mice cell line and } \mathrm{Cg} \text { - } \\
\text { Dock } 7^{\mathrm{m+/+}} \mathrm{Lepr}^{\mathrm{db} / \mathrm{J}} \text { mice } \\
\text { (Badal et al., 2016) }\end{array}$ & Msk2 & \\
\hline & & $\begin{array}{l}\text { Renal tissue, human } \\
\text { renal tubular cells }\end{array}$ & $\begin{array}{l}\text { DN patients and human } \\
\text { cell line (Ma et al., 2018) }\end{array}$ & ORAl1, TGFB1 & $\begin{array}{l}\text { Renal fibrosis and endothelial mesenchymal } \\
\text { transition }\end{array}$ \\
\hline miR-155 & Down & $\begin{array}{l}\text { Urine exosomes, } \\
\text { blood, renal tissues }\end{array}$ & $\begin{array}{l}\text { DN patients and C57BL6/ } \\
\text { J mice (Barutta et al., } \\
\text { 2013) }\end{array}$ & NA & Podocyte cells injury \\
\hline miR-205 & Down & $\begin{array}{l}\text { Renal tubules epithelial } \\
\text { cells }\end{array}$ & $\begin{array}{l}\text { Human cell line (Muratsu- } \\
\text { Ikeda et al., 2012) }\end{array}$ & $\begin{array}{l}\text { EGLN2, VEGF GLUT1, } \\
\text { HIF-1 } \alpha\end{array}$ & Renal injury \\
\hline $\mathrm{miR}-214$ & Down & $\begin{array}{l}\text { Renal, human renal } \\
\text { proximal tubular } \\
\text { epithelial cells }\end{array}$ & $\begin{array}{l}\text { DN mice and human cell } \\
\text { line (Yang et al., 2019) }\end{array}$ & UCP2 & Oxidative stress \\
\hline $\mathrm{miR}-374 \mathrm{a}$ & Down & $\begin{array}{l}\text { Renal biopsy, human } \\
\text { proximal tubular } \\
\text { epithelial cells }\end{array}$ & $\begin{array}{l}\text { DN patients and human } \\
\text { cell line (Yang et al., } \\
\text { 2018b) }\end{array}$ & CCL2 & Induce inflammatory response \\
\hline miR-423-5p & Down & $\begin{array}{l}\text { Renal biopsy, } \\
\text { podocyte cell }\end{array}$ & $\begin{array}{l}\text { DN patients and mice cell } \\
\text { line (Xu et al., 2018) }\end{array}$ & NOX4 & Oxidative stress and podocyte cells death \\
\hline $\operatorname{miR}-424$ & Up & $\begin{array}{l}\text { Urine exosomes, renal } \\
\text { tissues, human } \\
\text { mesangial cells }\end{array}$ & $\begin{array}{l}\text { T1DM patients with DN, } \\
\text { DN mice, and human cell } \\
\text { line, (Barutta et al., 2013) }\end{array}$ & NA & DN changes \\
\hline
\end{tabular}


TABLE 1 | Continued

\begin{tabular}{|c|c|c|c|c|c|}
\hline Noncoding RNA & Expression & Sample types & Origin/population & Molecular target & Function-pathogenesis \\
\hline $\operatorname{miR}-455-3 p$ & Down & $\begin{array}{l}\text { Mesangial cells, } \\
\text { proximal tubular } \\
\text { epithelial cells }\end{array}$ & $\begin{array}{l}\text { Human cell line (Wu et al., } \\
\text { 2018) }\end{array}$ & ROCK2 & Inflammation and fibrosis \\
\hline $\operatorname{miR}-574-3 p$ & Down & Plasma & $\begin{array}{l}\text { DN patients (Bijkerk et al., } \\
\text { 2015) }\end{array}$ & $\begin{array}{l}\text { ANGPT2/ANGPT1, } \\
\text { IGF1 }\end{array}$ & Effects renal function (eGFR and creatinine) \\
\hline miR-663 & Down & Renal tissue & $\begin{array}{l}\text { Hypertensive and } \\
\text { normotensive patients } \\
\text { (Marques et al., 2011) }\end{array}$ & AIFM1, APOE, RENIN & Hypertension in renal \\
\hline miR-874 & Down & Renal cortex & $\begin{array}{l}\text { STZ mice (Yao et al., } \\
\text { 2018) }\end{array}$ & $\begin{array}{l}\text { TLR4, IL6, IL1B, } \\
\text { TNFA }\end{array}$ & Podocyte cells proliferation and apoptosis \\
\hline Let-7a-5p & Down & $\begin{array}{l}\text { Renal tissue, } \\
\text { mesangial cells }\end{array}$ & $\begin{array}{l}\mathrm{db} / \mathrm{db} \text { mice and cell line } \\
\text { (Wang et al., 2019c) }\end{array}$ & HMGA2 & Renal hypertrophy and apoptosis \\
\hline \multicolumn{6}{|l|}{ Long noncoding RNAs } \\
\hline \multirow[t]{2}{*}{ ERBB4-IR } & Up & Renal tissue & $\begin{array}{l}\text { C57BL/6J mice (Zhou } \\
\text { et al., 2014) }\end{array}$ & Smad3, Tgfb & Renal fibrosis \\
\hline & & $\begin{array}{l}\text { Renal cortex, } \\
\text { mesangial cells, tubular } \\
\text { epithelial cells }\end{array}$ & $\begin{array}{l}\mathrm{db} / \mathrm{db} \text { mice and mice cell } \\
\text { (Sun et al., 2018b) (Sun } \\
\text { et al., 2018b) }\end{array}$ & $\begin{array}{l}\text { Smad3, Tgfb1, miR- } \\
29 b\end{array}$ & \\
\hline GAS5 & Up & $\begin{array}{l}\text { Human renal tubular } \\
\text { epithelial cell }\end{array}$ & $\begin{array}{l}\text { Human cell line (Lv et al., } \\
\text { 2019) }\end{array}$ & $\begin{array}{l}\text { miR-27a, P53, } \\
\text { CASP3, BNIP3 }\end{array}$ & Renal tubular epithelial cells apoptosis \\
\hline Gm4419 & Up & $\begin{array}{l}\text { High glucose } \\
\text { mesangial cells }\end{array}$ & Mice cells (Yi et al., 2017) & Nfkb & Renal inflammation and fibrosis. \\
\hline GM5524 & Up & $\begin{array}{l}\text { Renal tissues, } \\
\text { podocyte cells }\end{array}$ & $\begin{array}{l}\text { db/db mice (Feng et al., } \\
2018 \text { ) }\end{array}$ & $\begin{array}{l}\text { CASP3, BAX, LC3I, } \\
\text { LC3II Atg5, Atg7, BCl2 }\end{array}$ & Podocyte cells apoptosis and cells autophagy \\
\hline GM6135 & Up & Mesangial cells & $\begin{array}{l}\text { db/db mice (Ji et al., } \\
\text { 2019) }\end{array}$ & TLR4, miR-203 & Mesangial cells proliferation and apoptosis \\
\hline $\begin{array}{l}\text { LncRNA CJ241444- } \\
\text { miR-192 }\end{array}$ & Up & $\begin{array}{l}\text { Renal cortical tissues, } \\
\text { mesangial cells }\end{array}$ & $\begin{array}{l}\text { Obese type } 2 \text { diabetic db/ } \\
\mathrm{db} \text { mice and mouse cells } \\
\text { (Kato et al., 2013) }\end{array}$ & $\begin{array}{l}\text { Tgfb, Akt, Col1a2, } \\
\text { Col4A1, Smad, Ets1, } \\
\text { miR-192 }\end{array}$ & Mesangial cells fibrosis \\
\hline Lnc-MGC & Up & $\begin{array}{l}\text { Renal tissue, } \\
\text { mesangial cells }\end{array}$ & $\begin{array}{l}\text { STZ mice and human cell } \\
\text { (Kato et al., 2016) }\end{array}$ & TGFB1, SMAD, CHOP & $\begin{array}{l}\text { Renal toxicity and fibrosis, glomerular } \\
\text { hypertrophy, extracellular matrix accumulation, } \\
\text { and podocyte cells injury }\end{array}$ \\
\hline LncRNA NR_033515 & Up & $\begin{array}{l}\text { Serum, HEK293 T } \\
\text { cells,mesangial cells }\end{array}$ & $\begin{array}{l}\text { DN patients and mouse } \\
\text { cell (Gao et al., 2018) }\end{array}$ & $\begin{array}{l}\text { HAVCR1, PCNA, } \\
\text { CCND1TGFB1, P38, } \\
\text { ASK1, FN, ACTA2, } \\
\text { CDH, VIM, miR-743b- } \\
5 p\end{array}$ & EMT and cell proliferation \\
\hline \multirow[t]{4}{*}{$\begin{array}{l}\text { Metastasis associated } \\
\text { lung adenocarcinoma } \\
\text { transcript } 1 \text { (MALAT-1) }\end{array}$} & Up & $\begin{array}{l}\text { Umbilical vein } \\
\text { endothelial cells, STZ } \\
\text { mice }\end{array}$ & $\begin{array}{l}\text { Human cell line and mice } \\
\text { (Puthanveetil et al., 2015) }\end{array}$ & SAA3, TNF- $\alpha, I L-6$ & $\begin{array}{l}\text { Renal inflammation and fibrosis } \\
\text { Microvascular inflammation }\end{array}$ \\
\hline & & $\begin{array}{l}\text { Podocyte cells, HEK- } \\
293 \text { cells }\end{array}$ & $\begin{array}{l}\text { Human, C57BL/6 mice, } \\
\text { cell line (Hu et al., 2017) }\end{array}$ & CTNNBIP1, SRSF1 & Podocyte cells damage \\
\hline & & $\begin{array}{l}\text { Renal tissues, proximal } \\
\text { tubular epithelial cells }\end{array}$ & $\begin{array}{l}\text { Sprague Dawley rats and } \\
\text { human cell line (Li et al., } \\
2017 \text { b) }\end{array}$ & $\begin{array}{l}\text { miR-23c, ELAVL1, } \\
\text { NLRP3 }\end{array}$ & Renal tubular epithelial cell pyroptosis \\
\hline & & Serum & $\begin{array}{l}\text { ESRD patients with } \\
\text { diabetes (Fawzy et al., } \\
\text { 2018) }\end{array}$ & $\operatorname{miR}-499 a$ & DN changes \\
\hline \multirow[t]{2}{*}{ NEAT1 } & Up & Renal tissues & $\begin{array}{l}\text { Diabetic mice (Huang } \\
\text { et al., 2019) }\end{array}$ & $\begin{array}{l}\text { Akt, Mtor, Tgfb1, Fn, } \\
\text { Collv }\end{array}$ & Mesangial cell proliferation and fibrosis \\
\hline & & Renal tissues & $\begin{array}{l}\text { Sprague-Dawley rats } \\
\text { (Wang et al., 2018d) }\end{array}$ & $\begin{array}{l}\text { Zeb1, miR-27b-3p, } \\
\text { Ask1, fibronectin, } \\
\text { Tgfb1 }\end{array}$ & \\
\hline \multirow[t]{3}{*}{$\begin{array}{l}\text { Plasmacytoma variant } \\
\text { translocation (PVT1) }\end{array}$} & Up & Blood & $\begin{array}{l}\text { Gila River Indian } \\
\text { Community with T2DM } \\
\text { and DN T1DM patients } \\
\text { with DN (Hanson et al., } \\
\text { 2007) }\end{array}$ & NA & DN changes \\
\hline & & $\begin{array}{l}\text { Blood, human primary } \\
\text { renal cell }\end{array}$ & $\begin{array}{l}\text { Pima Indians with T1DM } \\
\text { and T2DM, and human } \\
\text { cell line }\end{array}$ & NA & \\
\hline & & Mesangial cells & $\begin{array}{l}\text { Human cell line (Alvarez } \\
\text { and DiStefano, 2011) }\end{array}$ & $\begin{array}{l}\text { FN1, COL4A1, } \\
\text { SERPINE1, TGFB1 }\end{array}$ & $\begin{array}{l}\text { Extracellular matrix accumulation and mesangial } \\
\text { cells fibrosis }\end{array}$ \\
\hline
\end{tabular}


TABLE 1 | Continued

\begin{tabular}{|c|c|c|c|c|c|}
\hline Noncoding RNA & Expression & Sample types & Origin/population & Molecular target & Function-pathogenesis \\
\hline \multirow[t]{2}{*}{ CASC2 } & Down & Serum, renal tissue & $\begin{array}{l}\text { DN patients (Wang et al., } \\
\text { 2018a) }\end{array}$ & NA & Podocyte cells deaths \\
\hline & & Serum, podocyte cells & $\begin{array}{l}\text { DN patients and mouse } \\
\text { (Yang et al., 2018a) }\end{array}$ & $J N K 1$ & \\
\hline \multirow[t]{2}{*}{ CYP4B1-PS1-001 } & Down & $\begin{array}{l}\text { Mesangial cells, renal } \\
\text { cortex }\end{array}$ & $\begin{array}{l}\text { db/db mice (Wang et al., } \\
2018 b)\end{array}$ & $\mathrm{NCl}$ & Renal proliferation and fibrosis \\
\hline & & $\begin{array}{l}\text { renal tissue, mesangial } \\
\text { cells, HEK293T }\end{array}$ & $\begin{array}{l}\text { C57BL/KsJ db/db mice, } \\
\text { and human and mouse } \\
\text { cell line (Wang et al., } \\
\text { 2016a) }\end{array}$ & $\begin{array}{l}\text { PCNA, CCND1, FN, } \\
\text { COLI }\end{array}$ & Mesangial cells proliferation and fibrosis \\
\hline ENSMUST00000147869 & Down & Renal cortex & $\begin{array}{l}\mathrm{db} / \mathrm{db} \text { and } \mathrm{db} / \mathrm{m} \text { mice } \\
\text { (Wang et al., 2016b) }\end{array}$ & Cур4a12a & Mesangial cells proliferation and fibrosis \\
\hline GM15645 & Down & $\begin{array}{l}\text { Renal tissue, podocyte } \\
\text { cells }\end{array}$ & $\begin{array}{l}\mathrm{db} / \mathrm{db} \text { mice (Feng et al., } \\
\text { 2018) }\end{array}$ & $\begin{array}{l}\text { CASP3, BAX, LC3I, } \\
\text { LC3II Atg5, Atg7, BCl2 }\end{array}$ & Podocyte cells apoptosis and cells autophagy \\
\hline LINC01619 & Down & $\begin{array}{l}\text { Renal biopsy, cortex, } \\
\text { podocyte cell }\end{array}$ & $\begin{array}{l}\text { T2DM patients, and STZ } \\
\text { Sprague Dawley rats (Bai } \\
\text { et al., 2018) }\end{array}$ & $\begin{array}{l}\text { FOXO1, ROS, CHOP, } \\
\text { GRP78, miR-27a }\end{array}$ & $\begin{array}{l}\text { Podocyte cells injury and apoptosis and } \\
\text { endoplasmic reticulum stress }\end{array}$ \\
\hline LncRNA 1700020l14Rik & Down & $\begin{array}{l}\text { Renal tissue, } \\
\text { mesangial cells }\end{array}$ & $\begin{array}{l}\mathrm{db} / \mathrm{db} \text { and } \mathrm{db} / \mathrm{m} \text { mice }(\mathrm{Li} \\
\text { et al., 2018a) }\end{array}$ & $\begin{array}{l}\text { Sirt1, Hif1a, Col4, Fn, } \\
\text { Tgfb 1, miR-34a-5p }\end{array}$ & Mesangial cells proliferation and fibrosis \\
\hline IncRNA RIAN & Down & $\begin{array}{l}\text { NIH3T3 cells and renal } \\
\text { tissue }\end{array}$ & $\begin{array}{l}\text { Mice and cell line (Bijkerk } \\
\text { et al., 2019) }\end{array}$ & $\begin{array}{l}\text { Acta2, Col1a1, } \\
\text { Smad2, Smad3, miR- } \\
150\end{array}$ & Myofibroblast formation \\
\hline \multirow[t]{4}{*}{$\begin{array}{l}\text { Taurine up-regulated } 1 \\
\text { (TUG-1) }\end{array}$} & Down & $\begin{array}{l}\text { Renal cortex, } \\
\text { mesangial, podocytes } \\
\text { cells }\end{array}$ & $\begin{array}{l}\mathrm{db} / \mathrm{db} \text { and } \mathrm{db} / \mathrm{m} \text { mice and } \\
\text { cell line (Long et al., 2016) }\end{array}$ & Ppargc1a & $\begin{array}{l}\text { Podocyte cells death and extracellular matrix } \\
\text { accumulation Reduce glomerular filtration rates } \\
\text { and podocyte cells apoptosis }\end{array}$ \\
\hline & & $\begin{array}{l}\text { Renal cortex, } \\
\text { mesangial cells }\end{array}$ & $\begin{array}{l}\text { C57BL/KsJ-db/db mice } \\
\text { and mice cell line (Duan et } \\
\text { al., 2017) }\end{array}$ & $\begin{array}{l}\text { miR-377, Pparg, } \\
\text { Serpine1, Tgfb1, Fn, } \\
\text { Col IV }\end{array}$ & $\begin{array}{l}\text { Extracellular matrix accumulation of mesangial } \\
\text { cells }\end{array}$ \\
\hline & & $\begin{array}{l}\text { Renal tissues, } \\
\text { podocyte cells }\end{array}$ & $\begin{array}{l}\text { Sprague Dawley rats and } \\
\text { mice cell line (Lei et al., } \\
\text { 2018) }\end{array}$ & Traf5 & Podocyte cells apoptosis \\
\hline & & $\begin{array}{l}\text { Renal biopsy, } \\
\text { podocyte cells }\end{array}$ & $\begin{array}{l}\text { DN patients and human } \\
\text { cell line (Shen et al., 2019) }\end{array}$ & PGC-1 $\alpha$, CHOP & $\begin{array}{l}\text { Podocyte cells apoptosis and endoplasmic } \\
\text { reticulum stress }\end{array}$ \\
\hline $\begin{array}{l}\text { Myocardial infarction } \\
\text { associated transcript } \\
\text { (MIAT) }\end{array}$ & Down & $\begin{array}{l}\text { Proximal convoluted } \\
\text { tubule, proximal } \\
\text { tubular epithelial cell } \\
\text { line }(\mathrm{HK}-2)\end{array}$ & $\begin{array}{l}\text { STZ Wistar rats and cell } \\
\text { line (Zhou et al., 2015) }\end{array}$ & $\begin{array}{l}\text { Nrf2, Acta2, Smad2/3, } \\
\text { Col1a1 }\end{array}$ & Renal cell apoptosis and fibrosis \\
\hline \multirow{2}{*}{$\begin{array}{l}\text { Circular noncoding RNAs } \\
\text { circRNA_15698 }\end{array}$} & & & & & \\
\hline & Up & $\begin{array}{l}\text { Renal cortex, } \\
\text { mesangial cells }\end{array}$ & $\begin{array}{l}\text { C57BL/KsJ-db/db mice } \\
\text { (Hu et al., 2019) }\end{array}$ & $\begin{array}{l}\text { Tgfb 1, Col1a1, Col4a1 } \\
\text { and Fn, miR-185 }\end{array}$ & Renal fibrosis \\
\hline
\end{tabular}

substrate-2, IRS2 (miR-141) (Li et al., 2018b), forkhead box proteins, and Foxo1 (miR-382) (Wang et al., 2018c) genes. Some of these miRNAs are found in circulating bio-fluids and therefore, could potentially be as biomarkers.

In contrast to the pro-DN miRNAs, miR-93 is the protective miRNA, with its expression was reduced in an animal model of $\mathrm{DN}$, and miR-93 is a direct regulator of the vascular endothelial growth factor A (Vegfa) (Long et al., 2010) and Msk2, a ribosomal S6 kinase of serine/threonine (Badal et al., 2016) expressions. Overexpression of miR-93 prevented the chromatin remodeling in podocyte cells after induction of hyperglycemia condition, via the suppression of Msk2 expression (a kinase that phosphorylates histone, H3S10) (Badal et al., 2016). Thus, making miR-93 as the potential therapeutic option to alleviate DN. Importantly, miR-93 also negatively regulates the Calcium release-activated calcium channel protein-1 (ORAI1), and reduction of miR-93 expression in DN caused an increase in ORAI1 expression and subsequently promoted TGFB-mediated ECM accumulation and fibrosis (Ma et al., 2018). Excessive ECM accumulation will eventually lead to glomerulosclerosis; therefore, it is the first and crucial step for progressive renal function loss.

\section{Long Noncoding RNAs in Renal Hypertrophy and ECM Accumulation}

Several lncRNAs are involved in the regulation of renal hypertrophy and ECM accumulation, though the evidence is quite limited (Table 1). One such lncRNA is the Plasmacytoma Variant Translocation-1 (PVT1), which is the first lncRNA to be associated with DN patients (Millis et al., 2007; Alvarez and DiStefano, 2011). Hyperglycemia induced higher PVT-1 expression and caused mesangial cell expansion through ECM accumulation of the FN, TGFB1, type IV collagen (COL4A1), and type 1 plasminogen activator inhibitor (PAI1) (Alvarez and DiStefano, 2011), as well as the myosin (MYC) proteins (Hanson et al., 2007). The knockdown of PVT-1 expression significantly caused the reduction of these molecules (Alvarez and DiStefano, 2011). Another reported IncRNA is the Nuclear Enriched 
Abundant Transcript-1 (NEAT1), which is also highly expressed due to hyperglycemia, and NEAT1 interacts with AKT/mTOR pathway (Huang et al., 2019). Inhibition of NEAT1 expression in an animal model of DN causes a reduction of TGFB1, FN, and COL4A1 production (Huang et al., 2019). Similarly, lncRNA ERBB4-IR also promotes renal fibrosis via the activation of the TGFB/SMAD3 pathway (Zhou et al., 2014; Sun et al., 2018b). Interestingly, knockdown of this lncRNA ERBB4-IR in DN mice protected the mice from having high albuminuria and creatinine, as well as prevented renal fibrosis (Sun et al., 2018b).

Opposite to PVT-1 and NEAT-1, a hyperglycemic condition caused downregulation of lncRNA, CYP4B1-PS1-001 expression, which increases nucleolin (NCL) protein expression (Wang et al., 2016a; Wang et al., 2018b). An increase in this protective lncRNA expression reduces the production of FN, COL4A1, and proliferation markers (PCNA and CCND1) in DN mice (Wang et al., 2018b). Another protective lncRNA is the lncRNA ENSMUST00000147869 that negatively regulate ECM protein accumulation in a hyperglycemic condition in DN mice (Wang et al., 2016b). Though, the exact role of this lncRNA is unknown.

\section{LncRNA-miRNA Interactions in Renal Hypertrophy and ECM Accumulation}

Understanding the interactions between miRNAs and lncRNAs to regulate genes involved in $\mathrm{DN}$ are important, as they will unravel the critical steps in DN progression. For example, in
ECM accumulation (Figure 1), previous studies in DN mice showed that interactions of lncRNA CJ241444-miR-192 activates TGFB1/SMAD signaling (Kato et al., 2013) and lncRNA Erbb4IR-miR-29b promotes the collagen genes expression, ECM accumulation and kidney injury (Sun et al., 2018b). In both of the studies (Kato et al., 2013; Sun et al., 2018a), the lncRNAs act as the miRNA sponge to exert the outcomes. Similarly, another reported lncRNA-miRNA interaction in DN is the lncRNA PVT-1 that mediates the ECM proteins accumulation via the actions of its-derived miRNAs, miR-1207-5p, and miR-1207-3p (Alvarez and DiStefano, 2011). Under the hyperglycemic condition, higher expression of both PVT-1 and its miRNAs led to an increase of the TGFB1/SMAD signaling pathway and further promoted the ECM protein accumulation and oxidative stress (Alvarez and DiStefano, 2011). Another example is the miR-379 cluster that consists of 40 miRNAs that are regulated by ER stress in DN, and lncRNA lncMGC is also hosted in this same cluster (Kato et al., 2016). LncMGC controls the expression of the miR-379 cluster, and the upregulation of this miRNAs cluster induces ECM accumulation and hypertrophy (Kato et al., 2016). Thus, inhibition of lncMGC expression could be used as a potential therapy for $\mathrm{DN}$ to reduce the miR-379 cluster's effects, following the ER stress. Besides that, lncRNA NEAT1 inhibition is also a potential therapeutic therapy, as this NEAT1 inhibition leads to the suppression of ECM accumulation, via the reduction of ASK1, FN, and TGFB1 production (Wang et al., 2018d). This NEAT1-mediated ECM suppression was due to its

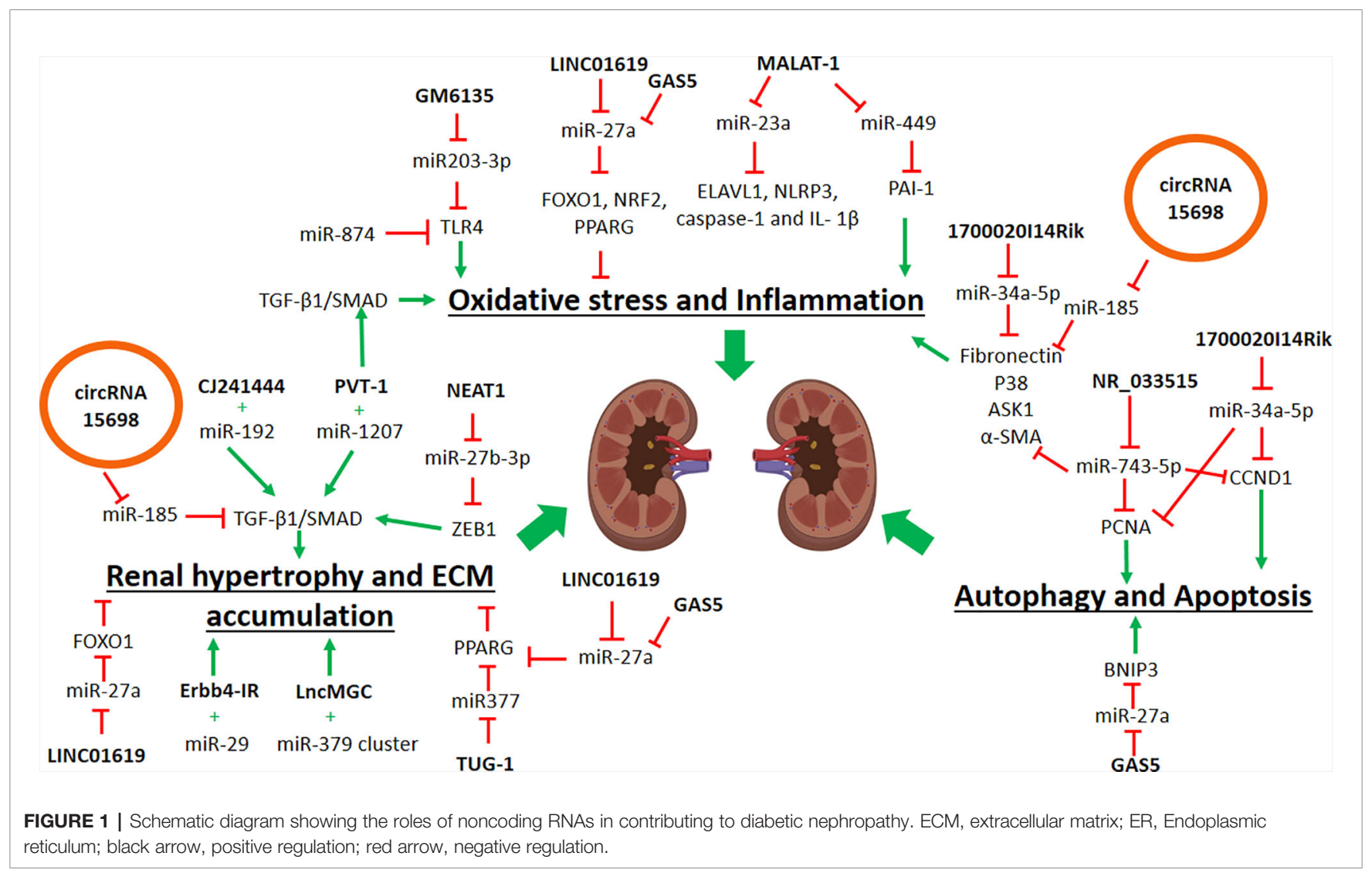


interaction with miR-27b-3p, and its target, the TGFB inducer, $Z e b 1$, in which NEAT1 is no longer suppressing the miR-27b-3p, which in turns activates the suppression of Zeb1, and thus can prevent DN progression (Wang et al., 2018d). Administration of the anti-apoptotic lncRNA, TUG-1, suppresses the miR-377 expression to increase the expression of miR-377's target gene PPARG and thus prevents ECM accumulation in DN mice (Duan et al., 2017). Therefore, treatment to increase TUG-1 expression may be beneficial to prevent DN development, though further studies are needed to confirm this potential treatment. By understanding these interactions between lncRNAs and their target miRNAs, these findings will allow for therapeutic targets selection to prevent ECM accumulation and possibly DN progression.

\section{Oxidative Stress and Inflammation MiRNAs in Oxidative Stress and Inflammation}

As for inducing the oxidative stress, miR-205 directly regulates the expression of Egl-9 Family Hypoxia Inducible Factor 2 (EGLN2), and miR-205 expression was reduced due to oxidative stress (Muratsu-Ikeda et al., 2012). Upon reduction of miR-205 expression, EGLN2 expression was increased and caused the reduction of the HIF-2A protein, and consequently increased the reactive oxygen species (ROS) level (Muratsu-Ikeda et al., 2012). Another oxidative stress-related miRNA is the miR377 , and its expression was higher in the renal tissue of DN mice (Wang et al., 2008), thus caused a reduction in the expression of superoxide dismutase 2 (SOD2), an enzyme responsible for removing free superoxide radicals. Several other miRNAs also regulate endoplasmic reticulum (ER) and oxidative stress in renal cells, such as miR-379 cluster, miR-494 (Kato et al., 2016), miR15b (Eissa et al., 2016a; Fu et al., 2019; Wang et al., 2019b), and miR-135a (He et al., 2014). Interestingly, miR-214 expression was reduced in peripheral blood of DN mice and overexpression of miR-214 in human renal proximal tubular epithelial cells prevented oxidative stress via upregulation of mitochondrial uncoupling protein-2 (UCP2) expression and its downstream pathway, the ROS/AKT/mTOR signaling pathway with significant reduction of ROS (Yang et al., 2019). Since the miR-214 reduction in circulating blood samples of $\mathrm{DN}$ mice was consistent with the renal expression of miR-214, and its regulation of the oxidative stress in kidney cells, thus miR-214 can be used as a potential oxidative stress biomarker. Another miRNA is the miR-25 that negatively regulates NADPH oxidase4 (Nox4) expression (an enzyme that produces ROS), and its expression was reduced in the renal tissue of $\mathrm{DN}$ rats (Fu et al., 2010). Importantly, the miR-25 expression is also regulated by Homeodomain-interacting protein kinase-2 (Hipk2) (Oh et al., 2016), indicating a complex regulation of HIPK2-miR-25-NOX4 in the maintenance of ROS. Furthermore, NOX4 gene expression is also regulated by $\mathrm{miR}-423-5 \mathrm{p}$, that were downregulated in kidney tissues of DN patients (Xu et al., 2018), further re-affirm the complex and tight regulation of NOX4 gene.

In terms of inflammation, miR-27a is a pro-inflammatory miRNA that negatively regulates the expression of nuclear factor erythroid 2-like 2 (NRF2) and peroxisome proliferator-activated receptor $\gamma(P P A R G)$, thus promotes the secretion of pro- inflammatory cytokines in $\mathrm{DN}$ animal and cell line models (Hou et al., 2016; Song et al., 2018; Zhou et al., 2018). Intriguingly, miR-27a expression is also negatively regulated by It $\ln 1$, an adipokine that usually reduced in metabolically dysregulated individuals (Song et al., 2018), indicating its role in metabolic syndrome. Another inflammatory miRNA is the miR-324-3p, and its expression was higher in glomerular and tubular tissues of DN mice (Macconi et al., 2012). Increased of this miR-324-3p expression led to renal inflammation via the suppression of prolyl endopeptidase gene expression (Prep), an enzyme that is responsible for regulating angiotensin metabolism (Macconi et al., 2012). In contrast to that, miR-374a is the antiinflammatory miRNA in $\mathrm{DN}$, which negatively regulates the expression of Monocyte chemo-attractant protein-1 (CCL2), a pro-inflammatory chemokine (Yang et al., 2018b). In DN patients, restoration of miR-374a expression in renal tubular epithelial cells prevented the inflammatory response (Yang et al., 2018b). Similarly, miR-874 negatively regulates the expression of Toll-like receptor-4 (Tlr4), and thus prevents the secretion of pro-inflammatory cytokines in DN mice (Yao et al., 2018). Another anti-inflammatory miRNA is the miR-455-3p that negatively regulates the expression of coil-containing protein kinase 2 (ROCK2), and consequently reduced the inflammatory cytokines and fibrosis markers in a human kidney cell line ( Wu et al., 2018). Identification of these anti-inflammatory and oxidative stress inhibitor miRNAs will allow for the possible use of these miRNAs mimics to prevent or reduce inflammation and oxidative stress. Since prolonged inflammation will eventually lead to fibrosis and renal damage, early intervention is necessary to prevent more severe complications.

\section{LncRNAs in Oxidative Stress and Inflammation}

A few lncRNAs also regulate renal inflammation and oxidative stress, though limited evidence is available. LncRNA GM4419 is a regulator for NF- $\mathrm{KB}$ signaling by directly interacts with the $\mathrm{p} 50$ protein, and thus, an increase of its expression promotes the inflammatory responses in renal mesangial cells upon stimulation of high glucose (Yi et al., 2017). Inhibition of this lncRNA significantly led to the reduction of inflammation and fibrosis (Yi et al., 2017). Another reported pro-inflammatory lncRNA is the Metastasis-associated lung adenocarcinoma transcript-1 (MALAT-1) that was increased in DN mice and interacted with serum amyloid A3 (Saa3), subsequently promotes the production of inflammatory factors (Il6 and Tnfa) in those DN mice (Puthanveetil et al., 2015). Similarly, the upregulation of lncRNA GM6135 expression in DN mice also promoted inflammation by increasing the expression of TLR4, which is a component of TLR-mediated signaling that is responsible for the secretion of pro-inflammatory cytokines (Ji et al., 2019).

In contrast, Myocardial infarction-associated transcript (MIAT) lncRNA is a protective lncRNA for the renal oxidative stress, by increasing the Nrf2 expression, a regulator of the antioxidant genes in DN mice (Zhou et al., 2015). In an animal model of DN, MIAT expression negatively correlated with serum creatinine level (Zhou et al., 2015), indicating that higher lncRNA MIAT expression is important for a healthy kidney. In contrast, another study showed that silencing the MIAT 
expression prevented myofibroblast formation in kidney fibrosis (Bijkerk et al., 2019), thus implying that MIAT is a pro-fibrotic lncRNA in tubulointerstitial fibrosis. Interestingly, in this same study (Bijkerk et al., 2019), it was the lncRNA RIAN that exhibited the anti-fibrotic role in tubulointerstitial fibrosis. Different roles of MIAT in mediating kidney injury or fibrosis can partially be explained via its interaction with miRNA targets in different pathways and mechanisms. For example, MIAT increased aortic vascular smooth muscle cell survival by inhibiting the expression of miR-145 (Chen et al., 2019), whereas MIAT promoted cardiac fibrosis via suppressing the miR-24 expression, a regulator of cardiac fibrosis genes (Eissa et al., 2016b). Therefore, it is important to unravel these molecular interactions to understand the exact mechanisms of DN progression.

\section{LncRNA-MiRNA Interactions in Oxidative Stress and Inflammation}

Several lncRNAs can regulate oxidative stress and inflammation in DN. Anti-oxidative stress lncRNA, LINC01619 expression was downregulated in DN patients' renal tissues, and since LINC01619 acts a sponge to miR-27a, and this reduction of LINC01619 expression causing miR-27a-mediated inhibition of FOXO1 expression, thus consequently leads to the ER stress and podocyte cells injury in DN (Bai et al., 2018). Intriguingly, miR27a also negatively regulates NRF2 and PPARG expressions, which are the anti-inflammatory factors (Hou et al., 2016; Song et al., 2018; Zhou et al., 2018). Thus, restoration of LINC01619 expression can prevent oxidative stress, inflammation, and podocyte cell injury in DN. Unlike LINC01619, the proinflammatory lncRNA, MALAT-1 was increased in DN rats and was shown to inhibit miR-23c expression by competitive binding, and thus increasing the expression of miR-23c targets, the pro-inflammatory proteins (ELAVL1, NLRP3, CASP1, and IL1B) in human kidney proximal tubular epithelial cells (Li et al., 2017b). Another miRNA target of MALAT-1 is miR-449, in which the suppression of miR-449 action led to an increase of the PAI1 expression (Fawzy et al., 2018). This suppression of miR449 expression correlated with the reduced GFR readings and increased uric acid and triglycerides in the blood of $\mathrm{DN}$ patients (Fawzy et al., 2018). Similar to MALAT-1, pro-inflammatory lncRNA, GM6135 increases the expression of Tlr4, by competitive binding to miR-203-3p, thus further activates the secretion of pro-inflammatory cytokines in DN mice (Ji et al., 2019). Interestingly, miR-874 also negatively regulates the Tlr4 gene expression (Yao et al., 2018). Thus further works are needed to determine whether IncRNA GM6135 could interact with miR874 and elevates TLR4 expression. Nevertheless, inhibition of these pro-inflammatory lncRNAs may alleviate the inflammatory response in renal cells via the up-regulation of their target miRNAs.

\section{Autophagy and Apoptosis MicroRNAs in Autophagy and Apoptosis}

Prolonged oxidative stress and inflammation can induce autophagy, apoptosis, and fibrosis in the kidney. In a study of human renal proximal tubular cells treated with high glucose concentration, overexpression of miR-155-5p led to the suppression of Sirtuin-1 (SIRT1) expression, which is a wellknown anti-apoptotic, anti-fibrotic and anti-inflammatory factor, and together with reduction of the two autophagy genes, LC3-II and ATG5 (Wang et al., 2018e). Consistent with this, in microalbuminuria patients, urinary exosome expression of miR130a and miR-145 were higher, whereas miR-155 and miR-424 expression were reduced (Barutta et al., 2013). Another profibrotic miRNA is the miR-133b, and its low expression in DN patients was in response to TGFB1 induction (Eissa et al., 2016b). This increased miR-133b expression inhibits E-cadherin (CDH1) and SIRT1 expression, as shown in DN mice (Sun et al., 2018a). Inhibition of miR-133b and miR-199b expression attenuated TGFB1 action, via the upregulation of SIRT1 expression (Sun et al., 2018a). Similar to SIRT1, Sirtuin-7 (SIRT7) expression is also important to prevent podocyte cells apoptosis, and low SIRT7 expression in hyperglycemic podocyte cells and DN mice, was due to being negatively regulated by miR-20b (Wang et al., 2017) Besides that, the miR-30 family members are also anti-fibrotic miRNAs, in which their expressions are reduced in DN patients (Eissa et al., 2016b). Their common target, a connective tissue growth factor $(C T G F)$, is a potent regulator for fibrosis, and its expression was higher in DN (Wu et al., 2014). Another regulator of CTFG is miR-26a, and its expression was low in DN patients and animal models (Koga et al., 2015).

In terms of apoptosis and cell death, miR-503 expression was higher in $\mathrm{DN}$ mice, and it negatively inhibits the expression of E2F transcription factor 3 (E2f3), and E2f3 is the transcription factor that is involved in the regulation of cell apoptosis, differentiation, and development (Zha et al., 2019). Reduction of the E2f3 expression leads to podocyte cells apoptosis and injury, induced by high glucose (Zha et al., 2019). Importantly, in the mice model of DN treated with Losartan (a drug for kidney disease treatment), the prevention of $\mathrm{DN}$ progression in those mice was evident with the inhibition of miR-503 action (Zhu et al., 2016), therefore confirming the role of miR-503 in contributing to podocyte cell death. Similarly, miR-181b is also the pro-apoptotic miRNA, and its expression was high in DN patients (Zhu et al., 2019). Increased miR-181b expression caused a reduction of TIMP3 expression, and inhibition of miR-181b caused up-regulation of TIMP3 expression together with increased mesangial cell viability (Zhu et al., 2019). Other pro-apoptotic miRNAs are the miR-770-5p that negatively regulates TP53-regulated inhibitor of apoptosis-1 (Triap1) expression in mice podocytes (Zhang et al., 2019); miR-320 that negatively regulates the transcription factor, Mafb in DN mice ( $\mathrm{He}$ et al., 2019); miR-182-5p that negatively regulates FOXO1, actin scaffolding protein $(C D 2 A P)$, and the regulator of cell death, BCL2 expressions in both human and animal models of DN (Stittrich et al., 2010; Peng et al., 2013; Ming et al., 2019); miR-134-5p that negatively regulates $B c l 2$ expression in DN mice (Qian et al., 2018); and all of these miRNAs were upregulated in $\mathrm{DN}$ and thus contributing to podocyte cell death. In contrast to that, miR-29a is anti-apoptotic miRNA in which its expression was low in DN mice that negatively regulates cannabinoid type-1 receptor (Cnr1) expression (Lin et al., 2014; Tung et al., 2019), and overexpression of miR-29a in animal model of DN 
prevented the secretion of pro-inflammatory and pro-fibrogenic factors, consequently attenuated renal hypertrophy (Tung et al., 2019). These findings provide the basis of using miRNAs as a therapeutic strategy to prevent or reduce the progression of $\mathrm{DN}$. However, it is important to note that many of these miRNAs also regulate different targets at the same time (Simpson et al., 2016), thus may unnecessarily causing dysregulation in a completely different pathway. Therefore, recent studies have embarked to characterize and develop these miRNA-based therapies for DN.

\section{LncRNAs in Autophagy and Apoptosis}

In terms of renal autophagy and apoptosis, lncRNA GM5524 expression was increased in DN mice and regulated these processes, upon stimulation with high glucose (Feng et al., 2018). GM5524 inhibits anti-apoptotic BCL2 expression and activates the LC3/ATG signaling pathway to promote autophagy (Feng et al., 2018). LncRNA GAS5 is also a proapoptotic IncRNA, in which GAS5 promoted the human renal tubular epithelial cells apoptosis under high glucose environment (Lv et al., 2019) In contrast to that, IncRNA GM15645 expression was low in DN mice and podocyte cells upon stimulation of high glucose, and this lncRNA acts opposite to lncRNA GM5524 in the regulation of podocyte cells apoptosis and autophagy (Feng et al., 2018). Similar to the anti-apoptotic effects of GM15645, lncRNA Taurine upregulated-1 (TUG-1), was downregulated in the $\mathrm{DN}$ and hyperglycemic condition, with evidence of renal damage and loss of podocyte cells in DN patients and animal model (Lei et al., 2018; Shen et al., 2019). Loss of TUG-1 expression reduces peroxisome proliferator-activated receptor gamma coactivator 1-alpha (Ppargcla) expression, as TUG-1 binds to the promoter region of the Ppargcla gene to increase its expression (Long et al., 2016). Consequently, loss of TUG-1 expression increases the tumor necrosis factor receptorassociated factor 5 (Traf5) expression and stimulates the podocyte cell death (Lei et al., 2018). Restoration of TUG-1 expression inhibits Traf5 protein production, not its mRNAs expression, and ameliorates podocyte cell survival (Lei et al., 2018). Another anti-apoptotic lncRNA is lncRNA NR_033515, in which its circulating expression was higher in $\mathrm{DN}$ patients, and this NR_033515 lncRNA can inhibit apoptosis by increasing the expression of proliferation genes (PCNA and CCND1) and fibrotic genes (P38, ASK1, FN, and $\alpha$-SMA) (Gao et al., 2018). Recently, Cancer susceptibility candidate 2 (CASC2) lncRNA has diagnostic potential for renal failure, as its reduced expression correlated with most significant renal damage in $\mathrm{DN}$ patients (Wang et al., 2018a). CASC2 prevents podocyte cell apoptosis through the inhibition of JNK signaling (Yang et al., 2018a). Although these findings of lncRNAs' role in DN progression is still lacking, there are potential biomarkers and therapeutic targets from these lncRNAs, particularly the anti-inflammatory lncRNA, MIAT, and anti-apoptotic lncRNA, TUG-1.

\section{LncRNAs-miRNAs Interactions in Autophagy and Apoptosis}

In terms of renal autophagy and apoptosis, lncRNA NR_033515 expression was higher in DN patients, and it inhibits miR-743b$5 \mathrm{p}$ action, and consequently increases the proliferation genes
(PCNA and CCND1), and fibrogenesis genes (P38, ASK1, FN, and $\alpha$-SMA) (Gao et al., 2018). Similarly, LncRNA 1700020 I14Rik inhibits the miR-34a-5p expression and increases the Sirt $1 /$ Hif- $1 \alpha$ signaling pathway, thus promotes the cell proliferation and fibrotic gene expressions (Tgfb1, Fn, and Col4a1) in DN mice (Li et al., 2018a). The pro-apoptotic role of lncRNA GAS5 was due by its competitive binding towards miR-27a (Lv et al., 2019). In hyperglycemic condition, GAS5 inhibits the regulatory action of miR-27a towards the BCL2 Interacting Protein 3 (BNIP3), thus causing an upregulation of $B N I P 3$ expression and renal tubular epithelial cell apoptosis ( $\mathrm{LV}$ et al., 2019). Another lncRNA is the lncRNA XIST, in which its expression was high in patients with primary membranous nephropathy, and this high expression of lncRNA XIST was due to Ang II treatment that promotes podocyte apoptosis (Jin et al., 2019). In this study, higher expression of lncRNA XIST inhibited the miR-217 action from suppressing the TLR4 expression; thus, leads to TRL4 activation of inflammatory and apoptosis effects (Jin et al., 2019). Interestingly, lncRNA XIST expression can be detected in the urine samples (Huang et al., 2014) thus suggesting the potential of this lncRNA as a biomarker for DN. From this evidence of lncRNA-miRNA interactions, there are two types of lncRNA regulations involved. One is that lncRNAs host the miRNAs and positively regulates these miRNAs. The second action is that lncRNAs act as a sponge to inhibit the miRNAs suppression of their target genes. Therefore, by identifying these interactions in the molecular regulation of DN progression, some of these lncRNAs can be used as potential biomarkers and therapeutic targets.

\section{CircRNAs-IncRNAs-miRNAs Interactions in DN}

Limited evidence is available to elucidate the interaction of circular RNA in DN progression. Only one study in DN mice showed that circRNA_15698 expression was higher in the DN mice, and knockdown expression of circRNA_15698 in mesangial cells led to reduced expression fibrotic genes (Colla1, Col4a1, and Fn) (Hu et al., 2019). In this study (Hu et al., 2019), circRNA_15698 acts as a sponge to miR-185, which in returns upregulates TGFB1 expression and promotes the ECM protein production. Therefore, inhibition of circRNA_15698 expression can prevent Tgfbl-mediated ECM accumulation and fibrosis in DN. Despite that there is limited information available for circRNAs in DN, the current findings imply that these circRNAs may be involved in DN progression, and the most exciting part is how their roles as miRNA sponge may interact with known lncRNA-miRNA interaction discussed above.

\section{LncRNA-miRNA-Based Treatment for DN}

MiRNAs can control the expression of genes involved in disease: thus, many miRNA-based therapies potentially can be as the alternative treatment options. In order for the miRNA-based treatment to work, the application of chemically engineered oligonucleotides to mimic (miRNA mimics) or silence the microRNAs (antagomiRs) were developed (Schena et al., 2013). One example of such techniques is the locked nucleic acid (LNA) 
molecular inhibitor to suppress a particular miRNA expression or action (Schena et al., 2013). Interestingly, LNA-miR-192 (to reduce miR-192 expression), showed some potential as a treatment for $\mathrm{DN}$, as it reduces the downstream miRNAs expression following the TGFB response, and the expression of critical genes in fibrosis progression in mice model (Putta et al., 2012). In agreement with most of the current treatments are available for DN patients, the application of the miRNA-based treatment in DN is mainly focused on to prevent renal fibrosis. Subcutaneous injection of antagomiR-miR-21 prevented renal fibrosis in chronic kidney disease mice by preventing both glomerular and tubular cell damage (Gomez et al., 2016). Another study focused on miR-29 family, in which the restoration of miR-29b expression in $\mathrm{DN}$ mice resulted in TGF- $\beta /$ Smad3 pathway suppression, reduced collagen matrix accumulation and inflammation (Chen et al., 2014a), thus implying that miRNA-based treatment could potentially be an alternative option for DN.

Although miRNA-based treatment is positively encouraging, the problem lies within the delivery method to exert this miRNAbased treatment. Most miRNAs are known to regulate many other target genes at the same time (Chen et al., 2014b; Li and Rana, 2014); thus, this treatment option may affect other unrelated pathways, if they are delivered as a whole-body effect or in vivo. Therefore, current research in miRNA-based therapies is shifted to focus on the delivery efficacy and safety, either by using a vector (virus particles or lipid particles) to target a specific route and localization to ensure a local tissue or region effect (Lanford et al., 2009; Simpson et al., 2016). Moreover, consideration of the therapeutic agent's size is also needed to make sure that it is small enough to cross the endothelium to the organ or site of interest and not will be filtered out by the kidney (Schena et al., 2013). However, for treating DN, this filtration problem could be an advantage to the miRNA-based treatment, as the tubular epithelial cells tend to reabsorb the molecules from the ultrafiltrate, thus reducing the loss (Schena et al., 2013). Therefore, there is some promise that miRNA-based treatments can be used for $\mathrm{DN}$ patients, though more future works are needed to validate these, especially in human clinical trials.

Several miRNA-based treatment or drugs have advanced to human clinical trials, though none was for treating DN. One such example is Miravirsen, which is a miR-122 inhibitor (LNAantisense oligonucleotide) that already entered phase II clinical trials to treat HCV infection in patients (Janssen et al., 2013). Subcutaneous Miravirsen injections resulted in dose-dependent reductions in HCV RNA levels without evidence of viral resistance (Janssen et al., 2013). Similarly, RG-101, which is another miR-122 inhibitor for $\mathrm{HCV}$-infected patients, has already completed a phase I trial (van der Ree et al., 2017). Many other miRNA-based treatments are currently in the development pipeline to initiate clinical trials for different human diseases; therefore, the option to use miRNA-based treatment for DN is a new research interest.

Another possible treatment is using the lncRNAs for DN. Targeting the lncRNA expression is favorable when compared to miRNAs, due to its functional role in transcriptional regulation, tissue-specific expression, cell- and disease-specific dysregulation. Because of the lncRNAs are predominantly in the nucleus, modified antisense oligonucleotides (ASOs) are used to target or silence the lncRNA in the nucleus by initiating the RNase H-dependent degradation (Kurreck et al., 2002). Such examples are the $2^{\prime}$-OMe RNA and LNA modifications at both the $5^{\prime}$ and the $3^{\prime}$ end (Kurreck et al., 2002). Though, the challenge is to make sure that the ASO binding is as intended to the lncRNA specific site, as the tertiary and secondary structures of lncRNAs can block such binding (Adams et al., 2017). Hence, to ensure the binding happens, the only solution is to provide or design more modified ASOs to target a single lncRNA, but the cost of each will be expensive. Moreover, the real challenge is the application of using this lncRNA-based treatment in vivo, and similar to miRNA-based treatments, the problems lie within their efficient delivery and efficacy. Another problem lies in the heterogeneous nature and un-conserved intron sequence of lncRNAs (Garitano Trojaola et al., 2013). Therefore, for some lncRNAs, a specific sequence of inhibitor needs to be designed specifically for each of them, mainly if the lncRNAs are from the animal models. Hence, further works need to be done to determine the possibility of using these miRNAs/lncRNAsbased treatments in $\mathrm{DN}$ progression as a future treatment option.

\section{CONCLUSION}

Many ncRNAs (miRNAs, lncRNAs, and circRNAs) are actively discovered to be involved in DN progression due to their regulations of the critical genes in these processes. Since most of these ncRNAs are stable in the biological fluids and can be identified easily without the surgical approach, they provide a strong basis as the potential biomarkers or therapeutic targets. Some of these ncRNAs are very specific towards their targets and localization. Although the exact molecular mechanism of DN progression is still unknown, several processes and pathways are known. Among these processes, ncRNAs involve in renal fibrosis and hypertrophy, ECM protein accumulation, cell autophagy, and apoptosis. Thus, concurrent with ncRNAs characterization, some research has proceeded to synthesize and producing ncRNAsbased treatments, with a few of these ncRNAs are already in the clinical trial phase. Therefore, these ncRNAs-based treatments will be an option for the treatment of $\mathrm{DN}$ in the future.

\section{AUTHOR CONTRIBUTIONS}

TL: wrote the manuscript. SSu: drafted and wrote the manuscript. NA and NAA: edited and critically revised the manuscript for intellectual contents. SSh, AA, and RJ: critically revised the manuscript for intellectual contents.

\section{FUNDING}

The manuscript was supported by the UKM University grant (GUP-2017-020). 


\section{REFERENCES}

Abu, N., and Jamal, R. (2016). Circular RNAs as promising biomarkers: a minireview. Front. Physiol. 7, 355. doi: 10.3389/fphys.2016.00355

Adams, B. D., Parsons, C., Walker, L., Zhang, W. C., and Slack, F. J. (2017). Targeting noncoding RNAs in disease. J. Clin. Invest. 127 (3), 761-771. doi: 10.1172/JCI84424

Ahmad, N., Jamal, R., Shah, S. A., Abdul Gafor, A. H., and Murad, N. A. A. (2019). Renin-angiotensin-aldosterone system gene polymorphisms and type 2 diabetic nephropathy in asian populations: an updated meta-analysis. Curr. Diabetes Rev. 15 (4), 263-276. doi: 10.2174/1573399814666180709100411

Alvarez, M. L., and DiStefano, J. K. (2011). functional characterization of the plasmacytoma variant translocation 1 gene (PVT1) in diabetic nephropathy. PloS One 6 (4), e18671. doi: 10.1371/journal.pone.0018671

Alvarez, M. L., and DiStefano, J. K. (2013). The role of non-coding RNAs in diabetic nephropathy: potential applications as biomarkers for disease development and progression. Diabetes Res. Clin. Pract. 99, 1-11. doi: 10.1016/J.DIABRES.2012.10.010

American Diabetes Association (2019). 11. Microvascular complications and foot care: standards of medical care in diabetes-2019. Diabetes Care 42 (Supplement 1), S124-S138. doi: 10.2337/dc19-s011

Andrea, J., Zollinger, L., Saely, C. H., Muendlein, A., Evangelakos, I., Nasias, D., et al. (2018). Circulating microRNAs -192 and -194 are associated with the presence and incidence of diabetes mellitus. Sci. Rep. 8, 14274. doi: 10.1038/ s41598-018-32274-9

Badal, S. S., Wang, Y., Long, J., Corcoran, D. L., Chang, B. H., Truong, L. D., et al. (2016). MiR-93 regulates Msk2-mediated chromatin remodelling in diabetic nephropathy. Nat. Commun. 7, 12076. doi: 10.1038/ncomms12076

Bai, X., Geng, J., Li, X., Wan, J., Liu, J., Zhou, Z., et al. (2018). Long noncoding RNA LINC01619 regulates MicroRNA-27a/Forkhead box protein O1 and endoplasmic reticulum stress-mediated podocyte injury in diabetic nephropathy. Antioxid. Redox Signaling 29, 355-376. doi: 10.1089/ars.2017.7278

Barutta, F., Tricarico, M., Corbelli, A., Annaratone, L., Pinach, S., Grimaldi, S., et al. (2013). Urinary exosomal microRNAs in incipient diabetic nephropathy. PloS One 8, e73798. doi: 10.1371/journal.pone.0073798

Bertone, P., Stolc, V., Royce, T. E., Rozowsky, J. S., Urban, A. E., Zhu, X., et al. (2004). Global identification of human transcribed sequences with genome tiling arrays. Science 306 (5705), 2242-2246. doi: 10.1126/science.1103388

Bhat, S. A., Ahmad, S. M., Mumtaz, P. T., Malik, A. A., Dar, M. A., Urwat, U., et al. (2016). Long non-coding RNAs: mechanism of action and functional utility. Non-coding RNA Res. 1 (1), 43-50. doi: 10.1016/j.ncrna.2016.11.002

Bijkerk, R., Duijs, J. M., Khairoun, M., Ter Horst, C. J., van der Pol, P., Mallat, M. J., et al. (2015). Circulating MicroRNAs associate with diabetic nephropathy and systemic microvascular damage and normalize after simultaneous pancreaskidney transplantation. Am. J. Transplant. 15 (4), 1081-1090. doi: 10.1111/ ajt.13072

Bijkerk, R., Au, Y. W., Stam, W., Duijs, J. M. G. J., Koudijs, A., Lievers, E., et al. (2019). Long non-coding RNAs rian and miat mediate myofibroblast formation in kidney fibrosis. Front. Pharmacol. 10, 215. doi: 10.3389/ fphar.2019.00215

Cao, Y., Yuan, G., Zhang, Y., and Lu, R. (2018). High glucose-induced circHIPK3 downregulation mediates endothelial cell injury. Biochem. Biophys. Res. Commun. 507 (1-4), 362-368. doi: 10.1016/j.bbrc.2018.11.041

Chau, B. N., Xin, C., Hartner, J., Ren, S., Castano, A. P., Linn, G., et al. (2012). MicroRNA-21 promotes fibrosis of the kidney by silencing metabolic pathways. Sci. Trans. Med. 4 (121), 121ra118. doi: 10.1126/ scitranslmed.3003205

Chawla, T., Sharma, D., and Singh, A. (2010). Role of the renin angiotensin system in diabetic nephropathy. World J. Diabetes 1 (5), 141-145. doi: 10.4239/ wjd.v1.i5.141

Chen, L.-L., and Yang, L. (2015). Regulation of circRNA biogenesis. RNA Biol. 12 (4), 381-388. doi: 10.1080/15476286.2015.1020271

Chen, H.-Y., Zhong, X., Huang, X. R., Meng, X.-M., You, Y., Chung, A. C., et al. (2014a). MicroRNA-29b inhibits diabetic nephropathy in $\mathrm{db} / \mathrm{db}$ mice. Mol. Ther. J. Am. Soc. Gene Ther. 22 (4), 842-853. doi: 10.1038/mt.2013.235

Chen, Y., Gao, D.-Y., and Huangb, L. (2014b). In vivo delivery of MiRNAs for cancer therapy: challenges and strategies. Adv. Drug Deliv. Rev. 81, 128-141. doi: 10.1016/j.addr.2014.05.009
Chen, X., Zhao, L., Xing, Y., and Lin, B. (2018). Down-regulation of microRNA-21 reduces inflammation and podocyte apoptosis in diabetic nephropathy by relieving the repression of TIMP3 expression. Biomed. Pharmacother. 108, $7-$ 14. doi: 10.1016/j.biopha.2018.09.007

Chen, S., Chen, H., Yu, C., Lu, R., Song, T., Wang, X., et al. (2019). Long noncoding RNA myocardial infarction associated transcript promotes the development of thoracic aortic by targeting microRNA-145 via the PI3K/Akt signaling pathway. J. Cell. Biochem. 120 (9), 1-9. doi: 10.1002/jcb.28695

Chen, L.-L. (2016). The biogenesis and emerging roles of circular RNAs. Nat. Rev. Mol. Cell Biol. 17, 205-211(2016. doi: 10.1038/nrm.2015.3

Chowdhury, A. R., Chetty, M., and Xuan Vinh, N. (2014). Evaluating influence of microRNA in reconstructing gene regulatory networks. Cognit. Neurodyn 8 (3), 251-259. doi: 10.1007/s11571-013-9265-x

Christos, A., Wang, K., Bernardo, J., Ellis, D., Orchard, T., Galas, D., et al. (2015). Urinary MicroRNA profiling predicts the development of microalbuminuria in patients with type 1 diabetes. J. Clin. Med. 4 (7), 1498-1517. doi: 10.3390/ jcm4071498

Cipriano, A., and Ballarino, M. (2018). The ever-evolving concept of the gene: the use of RNA/Protein experimental techniques to understand genome functions. Front. Mol. Biosci. 5, 20. doi: 10.3389/fmolb.2018.00020

Conn, S. J., Pillman, K. A., Toubia, J., Schreiber, A. W., Gregory, P. A., and Goodall, G. J. (2015). The RNA binding protein quaking regulates formation of circRNAs. Cell 160 (6), 1125-1134. doi: 10.1016/j.cell.2015.02.014

Denby, L., Ramdas, V., W. McBride, M., Wang, J., Robinson, H., McClure, J., et al. (2011). miR-21 and miR-214 are consistently modulated during renal injury in rodent models. Am. J. Pathol. 179 (2), 661-672. doi: 10.1016/j.ajpath. 2011.04.021

Deniz, E., and Erman, B. (2017). Long noncoding RNA (lincRNA), a new paradigm in gene expression control. Funct. Integr. Genomics 17 (2-3), 135143. doi: 10.1007/s10142-016-0524-x

Derrien, T., Johnson, R., Bussotti, G., Tanzer, A., Djebali, S., Tilgner, H., et al. (2012). The GENCODE v7 catalog of human long noncoding RNAs: analysis of their gene structure, evolution, and expression. Genome Res. 22 (9), 17751789. doi: 10.1101/gr.132159.111

Dhanoa, J. K., Sethi, R. S., Verma, R., Arora, J. S., and Mukhopadhyay, C. S. (2018). Long non-coding RNA: its evolutionary relics and biological implications in mammals: a review. J. Anim. Sci. Technol. 60, 25. doi: 10.1186/s40781-0180183-7

Djebali, S., Davis, C. A., Merkel, A., Dobin, A., Lassmann, T., Mortazavi, A., et al (2012). Landscape of transcription in human cells. Nature 489, 101-108. doi: 10.1038/nature11233

Du, W. W., Yang, W., Liu, E., Yang, Z., Dhaliwal, P., and Yang, B. B. (2016). Foxo3 circular RNA retards cell cycle progression via forming ternary complexes with p21 and CDK2. Nucleic Acids Res. 44 (6), 2846-2858. doi: 10.1093/nar/gkw027

Duan, L.-J., Ding, M., Hou, L.-J., Cui, Y.-T., Li, C.-J., and Yu, D.-M. (2017). Long noncoding RNA TUG1 alleviates extracellular matrix accumulation via mediating microRNA-377 targeting of PPAR $\gamma$ in diabetic nephropathy. Biochem. Biophys. Res. Commun. 484, 598-604. doi: 10.1016/ j.bbrc.2017.01.145

Ebert, M. S., and Sharp, P. A. (2012). Roles for microRNAs in conferring robustness to biological processes. Cell 149 (3), 515-524. doi: 10.1016/ j.cell.2012.04.005

Eissa, S., Matboli, M., Aboushahba, R., Bekhet, M. M., and Soliman, Y. (2016a). Urinary exosomal microRNA panel unravels novel biomarkers for diagnosis of type 2 diabetic kidney disease. J. Diabetes Complications 30 (8), 1585-1592. doi: 10.1016/j.jdiacomp.2016.07.012

Eissa, S., Matboli, M., and Bekhet, M. M. (2016b). Clinical verification of a novel urinary microRNA panal: $133 \mathrm{~b},-342$ and -30 as biomarkers for diabetic nephropathy identified by bioinformatics analysis. Biomed. Pharmacother. 83, 92-99. doi: 10.1016/j.biopha.2016.06.018

Eskildsen, T. V., Jeppesen, P. L., Schneider, M., Nossent, A. Y., Sandberg, M. B., Hansen, P. B., et al. (2013). Angiotensin II regulates microRNA-132/-212 in hypertensive rats and humans. Int. J. Mol. Sci. 14 (6), 11190-11207. doi: 10.3390/ijms140611190

Fang, Y., Wang, X., Li, W., Han, J., Jin, J., Su, F., et al. (2018). Screening of circular RNAs and validation of circANKRD36 associated with inflammation in patients with type 2 diabetes mellitus. Int. J. Mol. Med. 42 (4), 1865-1874. doi: 10.3892/ijmm.2018.3783 
Fawzy, M. S., Abu AlSel, B. T., Al Ageeli, E., Al-Qahtani, S. A., Abdel-Daim, M. M., and Toraih, E. A. (2018). Long non-coding RNA MALAT1 and microRNA499a expression profiles in diabetic ESRD patients undergoing dialysis: a preliminary cross-sectional analysis. Arch. Physiol. Biochemistry 126 (2), 172-182. doi: 10.1080/13813455.2018.1499119

Feng, Y., Chen, S., Xu, J., Zhu, Q., Ye, X., Ding, D., et al. (2018). Dysregulation of lncRNAs GM5524 and GM15645 involved in high-glucose-induced podocyte apoptosis and autophagy in diabetic nephropathy. Mol. Med. Rep. 18 (4), 3657-3664. doi: 10.3892/mmr.2018.9412

Fu, Y., Zhang, Y., Wang, Z., Wang, L., Wei, X., Zhang, B., et al. (2010). Regulation of NADPH oxidase activity is associated with miRNA-25-mediated NOX4 expression in experimental diabetic nephropathy. Am. J. Nephrol. 32 (6), 581589. doi: $10.1159 / 000322105$

Fu, Y., Wang, C., Zhang, D., Chu, X., Zhang, Y., and Li, J. (2019). miR-15b-5p ameliorated high glucose-induced podocyte injury through repressing apoptosis, oxidative stress, and inflammatory responses by targeting Sema3A. J. Cell. Physiol. 234 (11), 20869-20878. doi: 10.1002/jcp.28691

Gao, J., Wang, W., Wang, F., and Guo, C. (2018). LncRNA-NR_033515 promotes proliferation, fibrogenesis and epithelial-to-mesenchymal transition by targeting miR-743b-5p in diabetic nephropathy. Biomed. Pharmacother. 106, 543-552. doi: 10.1016/j.biopha.2018.06.104

Garitano Trojaola, A., Agirre, X., Prósper, F., and Fortes, P. (2013). Long noncoding RNAs in haematological malignancies. Int. J. Mol. Sci. 14 (8), 1538615422. doi: $10.3390 /$ ijms 140815386

Gheith, O., Farouk, N., Nampoory, N., Halim, M. A., and Al-Otaibi, T. (2016). Diabetic kidney disease: world wide difference of prevalence and risk factors. J. Nephropharmacol. 5, 49-56. doi: 10.4103/1110-9165.197379

Gomez, I. G., Nakagawa, N., and Duffield, J. S. (2016). MicroRNAs as novel therapeutic targets to treat kidney injury and fibrosis. Am. J. Physiol. Renal Physiol. 310 (10), F931-F944. doi: 10.1152/ajprenal.00523.2015

Ha, M., and Kim, V. N. (2014). Regulation of MicroRNA Biogenesis. Nat. Rev. Mol. Cell Biol. 15, 509-524. doi: 10.1038/nrm3838

Hagiwara, S., McClelland, A., and Kantharidis, P. (2013). MicroRNA in diabetic nephropathy: renin angiotensin, aGE/RAGE, and oxidative stress pathway. J. Diabetes Res. 2013, 173783. doi: 10.1155/2013/173783

Hanson, R. L., Craig, D. W., Millis, M. P., Yeatts, K. A., Kobes, S., Pearson, J. V., et al. (2007). Identification of PVT1 as a candidate gene for end-stage renal disease in type 2 diabetes using a pooling-based genome-wide single nucleotide polymorphism association study. Diabetes 56 (4), 975-983. doi: 10.2337/db061072

He, F., Peng, F., Xia, X., Zhao, C., Luo, Q., Guan, W., et al. (2014). MiR-135a promotes renal fibrosis in diabetic nephropathy by regulating TRPC1. Diabetologia 57 (8), 1726-1736. doi: 10.1007/s00125-014-3282-0

He, X., Ou, C., Xiao, Y., Han, Q., Li, H., and Zhou, S. (2017). LncRNAs: key players and novel insights into diabetes mellitus. Oncotarget 8, 71325-71341. doi: 10.18632/oncotarget.19921

He, M., Wang, J., Yin, Z., Zhao, Y., Hou, H., Fan, J., et al. (2019). MiR-320a induces diabetic nephropathy via inhibiting MafB. Aging (Albany NY) 11 (10), 30553079. doi: 10.18632/aging. 101962

Hon, K. W., Ab-Mutalib, N. S., Abdullah, N. M. A., Jamal, R., and Abu, N. (2019). Extracellular vesicle-derived circular RNAs confers chemoresistance in colorectal cancer. Sci. Rep. 9, 16497. doi: 10.1038/s41598-019-53063-y

Hou, X., Tian, J., Geng, J., Li, X., Tang, X., Zhang, J., et al. (2016). MicroRNA-27a promotes renal tubulointerstitial fibrosis via suppressing PPAR $\gamma$ pathway in diabetic nephropathy. Oncotarget 7 (30), 47760-47776. doi: 10.18632/ oncotarget.10283

Hu, M., Wang, R., Li, X., Fan, M., Lin, J., Zhen, J., et al. (2017). LncRNA MALAT1 is dysregulated in diabetic nephropathy and involved in high glucose-induced podocyte injury via its interplay with $\beta$-catenin. J. Cell. Mol. Med. 21 (11), 2732-2747. doi: 10.1111/jcmm.13189

Hu, W., Han, Q., Zhao, L., and Wang, L. (2019). Circular RNA circRNA_15698 aggravates the extracellular matrix of diabetic nephropathy mesangial cells via miR-185/TGF-ß31. J. Cell. Physiol. 234 (2), 1469-1476. doi: 10.1002/jcp.26959

Huang, Y.-S., Hsieh, H.-Y., Shih, H.-M., Sytwu, H.-K., and Wu, C.-C. (2014). Urinary Xist is a potential biomarker for membranous nephropathy. Biochem. Biophys. Res. Commun. 452 (3), 415-421. doi: 10.1016/j.bbrc.2014.08.077

Huang, S., Xu, Y., Ge, X., Xu, B., Peng, W., Jiang, X., et al. (2019). Long noncoding RNA NEAT1 accelerates the proliferation and fibrosis in diabetic nephropathy through activating Akt/mTOR signaling pathway. J. Cell. Physiol. 234, 1120011207. doi: $10.1002 /$ jcp. 27770

Janssen, H. L. A., Reesink, H. W., Lawitz, E. J., Zeuzem, S., Rodriguez-Torres, M., Patel, K., et al. (2013). Treatment of HCV infection by targeting MicroRNA. New Engl. J. Med. 368 (18), 1685-1694. doi: 10.1056/NEJMoa1209026

Jeck, W. R., Sorrentino, J. A., Wang, K., Slevin, M. K., Burd, C. E., Liu, J., et al. (2013). Circular RNAs are abundant, conserved, and associated with ALU repeats. RNA 19 (2), 141-157. doi: 10.1261/rna.035667.112

Jeppesen, P. L., Christensen, G. L., Schneider, M., Nossent, A. Y., Jensen, H. B., Andersen, D. C., et al. (2011). Angiotensin II type 1 receptor signalling regulates microRNA differentially in cardiac fibroblasts and myocytes. $\mathrm{Br}$. J. Pharmacol. 164 (2), 394-404. doi: 10.1111/j.1476-5381.2011.01375.x

Ji, T. T., Wang, Y. K., Zhu, Y. C., Gao, C. P., Li, X. Y., Li, J., et al. (2019). Long noncoding RNA Gm6135 functions as a competitive endogenous RNA to regulate toll-like receptor 4 expression by sponging miR-203-3p in diabetic nephropathy. J. Cell Physiol. 234 (5), 6633-6641. doi: 10.1002/jcp.27412

Jia, Y., Guan, M., Zheng, Z., Zhang, Q., Tang, C., Xu, W., et al. (2016). miRNAs in urine extracellular vesicles as predictors of early-stage diabetic nephropathy. J. Diabetes Res. 2016, 7932765. doi: 10.1155/2016/7932765

Jin, L.-w., Pan, M., Ye, H.-y., Zheng, Y., Chen, Y., Huang, W.-w., et al. (2019). Down-regulation of the long non-coding RNA XIST ameliorates podocyte apoptosis in membranous nephropathy via the miR-217-TLR4 pathway. Exp. Physiol. 104 (2), 220-230. doi: 10.1113/ep087190

Kato, M., Zhang, J., Wang, M., Lanting, L., Yuan, H., Rossi, J. J., et al. (2007). MicroRNA-192 in diabetic kidney glomeruli and its function in TGF-betainduced collagen expression via inhibition of E-box repressors. Proc. Natl. Acad. Sci. 104 (9), 3432-3437. doi: 10.1073/pnas.0611192104

Kato, M., Putta, S., Wang, M., Yuan, H., Lanting, L., Nair, I., et al. (2009). TGF- $\beta$ activates Akt kinase through a microRNA-dependent amplifying circuit targeting PTEN. Nat. Cell Biol. 11, 881-889. doi: 10.1038/ncb1897

Kato, M., Dang, V., Wang, M., Park, J. T., Deshpande, S., Kadam, S., et al. (2013). TGF- $\beta$ induces acetylation of chromatin and of Ets- 1 to alleviate repression of miR-192 in diabetic nephropathy. Sci. Signaling 6 (278), ra43. doi: 10.1126/ scisignal.2003389

Kato, M., Wang, M., Chen, Z., Bhatt, K., Oh, H. J., Lanting, L., et al. (2016). An endoplasmic reticulum stress-regulated lncRNA hosting a microRNA megacluster induces early features of diabetic nephropathy. Nat. Commun. 7, 12864. doi: $10.1038 /$ ncomms12864

Kelemen, E., Danis, J., Göblös, A., Bata-Csörgő, Z., and Széll, M. (2019). Exosomal long non-coding RNAs as biomarkers in human diseases. EJIFCC 30 (2), $224-$ 236

Kim, H., Bae, Y.-U., Jeon, J. S., Noh, H., Park, H. K., Byun, D. W., et al. (2019). The circulating exosomal microRNAs related to albuminuria in patients with diabetic nephropathy. J. Trans. Med. 17 (1), 236-236. doi: 10.1186/s12967019-1983-3

Koga, K., Yokoi, H., Mori, K., Kasahara, M., Kuwabara, T., Imamaki, H., et al. (2015). MicroRNA-26a inhibits TGF- $\beta$-induced extracellular matrix protein expression in podocytes by targeting CTGF and is downregulated in diabetic nephropathy. Diabetologia 58 (9), 2169-2180. doi: 10.1007/s00125015-3642-4

Krol, J., Loedige, I., and Filipowicz, W. (2010). The widespread regulation of microRNA biogenesis, function and decay. Nat. Rev. Genet. 11, 597-610. doi: $10.1038 / \mathrm{nrg} 2843$

Krupa, A., Jenkins, R., Luo, D. D., Lewis, A., Phillips, A., and Fraser, D. (2010). Loss of MicroRNA-192 promotes fibrogenesis in diabetic nephropathy. J. Am. Soc. Nephrol. 21 (3), 438-447. doi: 10.1681/ASN.2009050530

Kucherenko, M. M., and Shcherbata, H. R. (2018). miRNA targeting and alternative splicing in the stress response - events hosted by membrane-less compartments. J. Cell Sci. 131, jcs202002. doi: 10.1242/jcs.202002

Kurreck, J., Wyszko, E., Gillen, C., and Erdmann, V. A. (2002). Design of antisense oligonucleotides stabilized by locked nucleic acids. Nucleic Acids Res. 30 (9), 1911-1918. doi: 10.1093/nar/30.9.1911

Lanford, R. E., Hildebrandt-Eriksen, E. S., Petri, A., Persson, R., Lindow, M., Munk, M. E., et al. (2009). Therapeutic Silencing of MicroRNA-122 in primates with chronic hepatitis C Virus Infection. Science 327 (5962), 198-201. doi: $10.1126 /$ science. 1178178

Lei, X., Zhang, L., Li, Z., and Ren, J. (2018). Astragaloside IV/lncRNA-TUG1/ TRAF5 signaling pathway participates in podocyte apoptosis of diabetic 
nephropathy rats. Drug Des. Dev. Ther. 12, 2785-2793. doi: 10.2147/ DDDT.S166525

Leti, F., and DiStefano, J. K. (2017). Long noncoding RNAs as diagnostic and therapeutic targets in type 2 diabetes and related complications. Genes 8 (8), 207. doi: 10.3390 /genes 8080207

Li, Z., and Rana, T. M. (2014). Therapeutic targeting of MicroRNAs: current status and future challenges. Nat. Rev. Drug Discov. 13, 622-638. doi: 10.1038/ $\operatorname{nrd} 4359$

Li, Z., Huang, C., Bao, C., Chen, L., Lin, M., Wang, X., et al. (2015). Exon-intron circular RNAs regulate transcription in the nucleus. Nat. Struct. Mol. Biol. 22 (3), 256-264. doi: 10.1038/nsmb.2959

Li, H., Zhu, X., Zhang, J., and Shi, J. (2017a). MicroRNA-25 inhibits high glucoseinduced apoptosis in renal tubular epithelial cells via PTEN/AKT pathway. BioMed. Pharmacother. 96, 471-479. doi: 10.1016/j.biopha.2017.10.019

Li, X., Zeng, L., Cao, C., Lu, C., Lian, W., Han, J., et al. (2017b). Long noncoding RNA MALAT1 regulates renal tubular epithelial pyroptosis by modulated miR-23c targeting of ELAVL1 in diabetic nephropathy. Exp. Cell Res. 350 (2), 327-335. doi: 10.1016/j.yexcr.2016.12.006

Li, A., Peng, R., Sun, Y., Liu, H., Peng, H., and Zhang, Z. (2018a). LincRNA 1700020I14Rik alleviates cell proliferation and fibrosis in diabetic nephropathy via MIR-34a-5p/Sirt1/HIF-1 $\alpha$ signaling. Cell Death Dis. 9 (5), 461. doi: $10.1038 /$ s41419-018-0527-8

Li, Y., Huang, D., Zheng, L., Cao, H., and Fan, Z. (2018b). Effect of microRNA-141 on the development of diabetic nephropathy through regulating AKT/AMPK signaling pathway by targeting insulin receptor substrate 2. J. Cell Biochem. 120 (5), 8008-8015. doi: $10.1002 /$ jcb.28078

Lin, C. L., Lee, P. H., Hsu, Y. C., Lei, C. C., Ko, J. Y., Chuang, P. C., et al. (2014). MicroRNA-29a promotion of nephrin acetylation ameliorates hyperglycemiainduced podocyte dysfunction. J. Am. Soc. Nephrol. 25 (8), 1698-1709. doi: 10.1681/ASN.2013050527

Lin, Y.-C., Chang, Y.-H., Yang, S.-Y., Wu, K.-D., and Chu, T.-S. (2018). Update of pathophysiology and management of diabetic kidney disease. J. Formosan Med. Assoc. 117 (8), 662-675. doi: 10.1016/J.JFMA.2018.02.007

Liu, Z., Zhang, H., Liu, Z., Zhang, H., Liu, Z., and Zhang, H. (2017). LncRNA plasmacytoma variant translocation 1 is an oncogene in bladder urothelial carcinoma. Oncotarget 8, 64273-64282. doi: 10.18632/oncotarget.19604

Long, J., Wang, Y., Wang, W., Chang, B. H. J., and Danesh, F. R. (2010). Identification of microRNA-93 as a novel regulator of vascular endothelial growth factor in hyperglycemic conditions. J. Biol. Chem. 285, 23457-23465. doi: 10.1074/jbc.M110.136168

Long, J., Badal, S. S., Ye, Z., Wang, Y., Ayanga, B. A., Galvan, D. L., et al. (2016). Long noncoding RNA Tug1 regulates mitochondrial bioenergetics in diabetic nephropathy. J. Clin. Invest. 126 (11), 4205-4218. doi: 10.1172/JCI87927

Lubelsky, Y., and Ulitsky, I. (2018). Sequences enriched in Alu repeats drive nuclear localization of long RNAs in human cells. Nature 555, pages107-111. doi: $10.1038 /$ nature 25757

Lv, L., Li, D., Tian, F., Li, X., Zhang, J., and Yu, X. (2019). Silence of IncRNA GAS5 alleviates high glucose toxicity to human renal tubular epithelial HK-2 cells through regulation of miR-27a. Artif. Cells Nanomed Biotechnol. 47 (1), 22052212. doi: $10.1080 / 21691401.2019 .1616552$

Ma, J., Zhang, L., Hao, J., Li, N., Tang, J., and Hao, L. (2018). Up-regulation of microRNA-93 inhibits TGF- $\beta 1$-induced EMT and renal fibrogenesis by downregulation of orail. J. Pharmacol. Sci. 136 (4), 218-227. doi: 10.1016/ j.jphs.2017.12.010

Ma, Y., Shi, J., Wang, F., Li, S., Wang, J., Zhu, C., et al. (2019). MiR-130b increases fibrosis of HMC cells by regulating the TGF-betal pathway in diabetic nephropathy. J. Cell Biochem. 120 (3), 4044-4056. doi: 10.1002/jcb.27688

Macconi, D., Tomasoni, S., Romagnani, P., Trionfini, P., Sangalli, F., Mazzinghi, B., et al. (2012). MicroRNA-324-3p promotes renal fibrosis and is a target of ACE inhibition. J. Am. Soc. Nephrol. 23 (9), 1496-1505. doi: 10.1681/ASN.2011121144

Maity, S., Bera, A., Ghosh-Choudhury, N., Das, F., Kasinath, B. S., and Choudhury, G. G. (2018). microRNA-181a downregulates deptor for TGF $\beta$-induced glomerular mesangial cell hypertrophy and matrix protein expression. Exp. Cell Res. 364 (1), 5-15. doi: 10.1016/j.yexcr.2018.01.021

Marques, F. Z., Campain, A. E., Tomaszewski, M., Zukowska-Szczechowska, E., Yang, Y. H., Charchar, F. J., et al. (2011). Gene expression profiling reveals renin mRNA overexpression in human hypertensive kidneys and a role for
microRNAs. Hypertension 58 (6), 1093-1098. doi: 10.1161/ HYPERTENSIONAHA.111.180729

Marques, F. Z., Romaine, S. P., Denniff, M., Eales, J., Dormer, J., Garrelds, I. M., et al. (2015). Signatures of miR-181a on the renal transcriptome and blood pressure. Mol. Med. (Cambridge Mass.) 21 (1), 739-748. doi: 10.2119/ molmed.2015.00096

Memczak, S., Jens, M., Elefsinioti, A., Torti, F., Krueger, J., Rybak, A., et al. (2013). Circular RNAs are a large class of animal RNAs with regulatory potency. Nature 495, 333-338(2013. doi: 10.1038/nature11928

Millis, M. P., Bowen, D., Kingsley, C., Watanabe, R. M., and Wolford, J. K. (2007). Variants in the plasmacytoma variant translocation gene (PVT1) are associated with end-stage renal disease attributed to type 1 diabetes. Diabetes 56 (12), 3027-3032. doi: 10.2337/db07-0675

Ming, L., Ning, J., Ge, Y., Zhang, Y., and Ruan, Z. (2019). Excessive apoptosis of podocytes caused by dysregulation of microRNA-182-5p and CD2AP confers to an increased risk of diabetic nephropathy. J. Cell. Biochem. 120, 1651616523. doi: $10.1002 /$ jcb. 28911

Muratsu-Ikeda, S., Nangaku, M., Ikeda, Y., Tanaka, T., Wada, T., and Inagi, R. (2012). Downregulation of miR-205 modulates cell susceptibility to oxidative and endoplasmic reticulum stresses in renal tubular cells. PloS One 7 (7), e41462. doi: 10.1371/journal.pone.0041462

O’Brien, J., Hayder, H., Zayed, Y., and Peng, C. (2018). Overview of MicroRNA biogenesis, mechanisms of actions, and circulation. Front. Endocrinol. (Lausanne) 9, 402. doi: 10.3389/fendo.2018.00402

Oh, H. J., Kato, M., Deshpande, S., Zhang, E., Sadhan, D., Lanting, L., et al. (2016). Inhibition of the processing of miR-25 by HIPK2-Phosphorylated-MeCP2 induces NOX4 in early diabetic nephropathy. Sci. Rep. 6, 38789. doi: 10.1038/ srep38789

Park, J. T., Kato, M., Yuan, H., Castro, N., Lanting, L., Wang, M., et al. (2013). FOG2 protein down-regulation by transforming growth factor- $\beta 1$-induced MicroRNA-200b/c leads to Akt kinase activation and glomerular mesangial hypertrophy related to diabetic nephropathy. J. Biol. Chem. 288, 22469-22480. doi: 10.1074/jbc.M113.453043

Peng, X., Li, W., Yuan, L., Mehta, R. G., Kopelovich, L., and McCormick, D. L. (2013). Inhibition of proliferation and induction of autophagy by atorvastatin in PC3 prostate cancer cells correlate with downregulation of Bcl2 and upregulation of miR-182 and p21. PloS One 8 (8), e70442. doi: 10.1371/ journal.pone.0070442

Piero, R., Paolo, C., and Giuseppe, R. (2010). The RAAS in the pathogenesis and treatment of diabetic nephropathy. Nat. Rev. Nephrol. 6, 319-330. doi: 10.1038/ nrneph. 2010.58

Puthanveetil, P., Chen, S., Feng, B., Gautam, A., and Chakrabarti, S. (2015). Long non-coding RNA MALAT1 regulates hyperglycaemia induced inflammatory process in the endothelial cells. J. Cell. Mol. Med. 19 (6), 1418-1425. doi: $10.1111 /$ jcmm. 12576

Putta, S., Lanting, L., Sun, G., Lawson, G., Kato, M., and Natarajan, R. (2012). Inhibiting MicroRNA-192 ameliorates renal fibrosis in diabetic nephropathy. J. Am. Soc. Nephrol. 23 (3), 458-469. doi: 10.1681/asn.2011050485

Qian, X., Tan, J., Liu, L., Chen, S., You, N., Yong, H., et al. (2018). MicroRNA-134$5 \mathrm{p}$ promotes high glucose-induced podocyte apoptosis by targeting bcl-2. Am. J. Transl. Res. 10 (3), 989-997.

Quinn, J. J., and Chang, H. Y. (2015). Unique features of long non-coding RNA biogenesis and function. Nat. Rev. Genet. 17, 47-62. doi: 10.1038/nrg.2015.10

Remuzzi, G., Perico, N., Macia, M., and Ruggenenti, P. (2005). The role of reninangiotensin-aldosterone system in the progression of chronic kidney disease. Kidney Int. 68 (99), S57-65. doi: 10.1111/j.1523-1755.2005.09911

Rodriguez, A., Griffiths-Jones, S., Ashurst, J. L., and Bradley, A. (2004). Identification of mammalian microRNA host genes and transcription units. Genome Res. 14 (10a), 1902-1910. doi: 10.1101/gr.2722704

Sayilar, E. I., Gullulu, M., Tuncel, E., Peynirci, H., Alemdar, A., Tunca, B., et al. (2016). Biomarker potential of urine miR-451 at different stages of diabetic nephropathy. J. Diabetes Metab. 7, 650. doi: 10.4172/2155-6156.1000650

Schena, F. P., Serino, G., and Sallustio, F. (2013). MicroRNAs in kidney diseases: new promising biomarkers for diagnosis and monitoring. Nephrol. Dialysis Transplant. 29 (4), 755-763. doi: 10.1093/ndt/gft223

Shaheer, A. K., Tharayil, J. K., and Krishna, P. W. (2017). A comparative study of high sensitivity c-reactive protein and metabolic variables in type 2 diabetes 
mellitus with and without nephropathy. J. Clin. Diagn. Res. JCDR 11 (9), BC01-BC04. doi: 10.7860/JCDR/2017/30272.10528

Shen, H., Ming, Y., Xu, C., Xu, Y., Zhao, S., and Zhang, Q. (2019). Deregulation of long noncoding RNA (TUG1) contributes to excessive podocytes apoptosis by activating endoplasmic reticulum stress in the development of diabetic nephropathy. J. Cell. Physiol. 234, 15123-15133. doi: 10.1002/jcp.28153

Simpson, K., Wonnacott, A., Fraser, D. J., and Bowen, T. (2016). MicroRNAs in diabetic nephropathy: from biomarkers to therapy. Curr. Diabetes Rep. 16 (3), 35. doi: 10.1007/s11892-016-0724-8

Song, J., Zhang, H., Sun, Y., Guo, R., Zhong, D., Xu, R., et al. (2018). Omentin-1 protects renal function of mice with type 2 diabetic nephropathy via regulating miR-27a-Nrf2/Keap1 axis. BioMed. Pharmacother. 107, 440-446. doi: 10.1016/ j.biopha.2018.08.002

Stephen, M. R., M.Reed, S., Warwick, M. B., and Debra, C. S. (2004). "Disorders of the Endocrine Pancreas," in Pathophysiology of Disease: An Introduction to Clinical Medicine, 2nd ed. Eds. M. R. Stephen, S. M. Reed, M. B. Warwick, C. S. Debra and W. B. Saunders (The McGraw-Hill Companies), 1295-1379.

Stittrich, A.-B., Haftmann, C., Sgouroudis, E., Kühl, A. A., Hegazy, A. N., Panse, I., et al. (2010). The microRNA miR-182 is induced by IL-2 and promotes clonal expansion of activated helper T lymphocytes. Nat. Immunol. 11 (11), 10571062. doi: 10.1038/ni.1945

Sulaiman, S. A., Abdul Murad, N. A., Mohamad Hanif, E. A., Abu, N., and Jamal, R. (2018). "Prospective Advances in Circular RNA Investigation," in Circular RNAs: Biogenesis and Functions. Ed. J. Xiao (Singapore: Springer Singapore), 357-370.

Sulaiman, S. A., Muhsin, N. I. A., and Jamal, R. (2019). Regulatory non-coding RNAs network in non-alcoholic fatty liver disease. Front. Physiol. 10, 279. doi: $10.3389 /$ fphys.2019.00279

Sun, S. F., Tang, P. M. K., Feng, M., Xiao, J., Huang, X. R., Li, P., et al. (2018a). Novel LncRNA Erbb4-IR promotes diabetic kidney injury in $\mathrm{Db} / \mathrm{Db}$ mice by targeting MiR-29b. Diabetes 67 (4), 731-744. doi: 10.2337/db17-0816

Sun, Z., Ma, Y., Chen, F., Wang, S., Chen, B., and Shi, J. (2018b). miR-133b and miR-199b knockdown attenuate TGF- $\beta 1$-induced epithelial to mesenchymal transition and renal fibrosis by targeting SIRT1 in diabetic nephropathy. Eur. J. Pharmacol. 837, 96-104. doi: 10.1016/j.ejphar.2018.08.022

Thomson, D. W., and Dinger, M. E. (2016). Endogenous microRNA sponges: evidence and controversy. Nat. Rev. Genet. 17, 272-283. doi: 10.1038/ nrg. 2016.20

Tung, C. W., Ho, C., Hsu, Y. C., Huang, S. C., Shih, Y. H., and Lin, C. L. (2019). MicroRNA-29a attenuates diabetic glomerular injury through modulating cannabinoid receptor 1 signaling. Molecules 24 (2), 264. doi: 10.3390/ molecules 24020264

Tziomalos, K., and Athyros, V. G. (2015). Diabetic nephropathy: new risk factors and improvements in diagnosis. Rev. Diabetic Stud. 12 (1-2), 110-118. doi: 10.1900/RDS.2015.12.110

van der Ree, M. H., de Vree, J. M., Stelma, F., Willemse, S., van der Valk, M., Rietdijk, S., et al. (2017). Safety, tolerability, and antiviral effect of RG-101 in patients with chronic hepatitis C: a phase $1 \mathrm{~B}$, double-blind, randomised controlled trial. Lancet 389 (10070), 709-717. doi: 10.1016/S0140-6736(16) 31715-9

Wang, Q., Wang, Y., Minto, A. W., Wang, J., Shi, Q., Li, X., et al. (2008). MicroRNA377 is up-regulated and can lead to increased fibronectin production in diabetic nephropathy. FASEB J. 12, 4126-4135. doi: 10.1096/fj.08-112326

Wang, K., Zhang, S., Weber, J., Baxter, D., and Galas, D. J. (2010). Export of microRNAs and microRNA-protective protein by mammalian cells. Nucleic Acids Res. 38 (20), 248-7259. doi: 10.1093/nar/gkq601

Wang, M., Wang, S., Yao, D., Yan, Q., and Lu, W. (2016a). A novel long noncoding RNA CYP4B1-PS1-001 regulates proliferation and fibrosis in diabetic nephropathy. Mol. Cell. Endocrinol. 426, 136-145. doi: 10.1016/ j.mce.2016.02.020

Wang, M., Yao, D., Wang, S., Yan, Q., and Lu, W. (2016b). Long non-coding RNA ENSMUST00000147869 protects mesangial cells from proliferation and fibrosis induced by diabetic nephropathy. Endocrine 54 (1), 81-92. doi: 10.1007/s12020-016-0950-5

Wang, X., Lin, B., Nie, L., and Li, P. (2017). microRNA-20b contributes to high glucose-induced podocyte apoptosis by targeting SIRT7. Mol. Med. Rep. 16 (4), 5667-5674. doi: 10.3892/mmr.2017.7224

Wang, L., Su, N., Zhang, Y., and Wang, G. (2018a). Clinical significance of serum lncRNA cancer susceptibility candidate 2 (CASC2) for chronic renal failure in patients with type 2 diabetes. Med. Sci. Monit. 24, 6079-6084. doi: 10.12659/ msm. 909510

Wang, S., Chen, X., Wang, M., Yao, D., Chen, T., Yan, Q., et al. (2018b). Long noncoding RNA CYP4B1-PS1-001 inhibits proliferation and fibrosis in diabetic nephropathy by interacting with nucleolin. Cell. Physiol. Biochem. 49, 21742187. doi: $10.1159 / 000493821$

Wang, S., Wen, X., Han, X. R., Wang, Y. J., Shen, M., Fan, S. H., et al. (2018c). Repression of microRNA-382 inhibits glomerular mesangial cell proliferation and extracellular matrix accumulation via FoxO1 in mice with diabetic nephropathy. Cell Prolif 51 (5), e12462. doi: 10.1111/cpr.12462

Wang, X., Xu, Y., Zhu, Y. C., Wang, Y. K., Li, J., Li, X. Y., et al. (2018d). LncRNA NEAT1 promotes extracellular matrix accumulation and epithelial-tomesenchymal transition by targeting miR-27b-3p and ZEB1 in diabetic nephropathy. J. Cell. Physiol. 234 (8), 12926-12933. doi: 10.1002/jcp.27959

Wang, Y., Zheng, Z.-j., Jia, Y.-j., Yang, Y.-l., and Xue, Y.-m. (2018e). Role of p53/ miR-155-5p/sirt1 loop in renal tubular injury of diabetic kidney disease. J. Transl. Med. 16 (1), 146. doi: 10.1186/s12967-018-1486-7

Wang, J., Shen, L., Hong, H., Li, J., Wang, H., and Li, X. (2019a). Atrasentan alleviates high glucose-induced podocyte injury by the microRNA-21/forkhead box O1 axis. Eur. J. Pharmacol. 852, 142-150. doi: 10.1016/j.ejphar.2019.03.013

Wang, L.p., Gao, Y.z., Song, B., Yu, G., Chen, H., Zhang, Z.w., et al. (2019b). MicroRNAs in the progress of diabetic nephropathy: a systematic review and meta-analysis. Evidence-Based Complement. Altern. Med. 2019, 3513179. doi: $10.1155 / 2019 / 3513179$

Wang, T., Zhu, H., Yang, S., and Fei, X. (2019c). Let-7a-5p may participate in the pathogenesis of diabetic nephropathy through targeting HMGA2. Mol. Med. Rep. 19 (5), 4229-4237. doi: 10.3892/mmr.2019.10057

Winter, J., Jung, S., Keller, S., Gregory, R. I., and Diederichs, S. (2009). Many roads to maturity: microRNA biogenesis pathways and their regulation. Nat. Cell Biol. 11, 228-234. doi: 10.1038/ncb0309-228

Wu, J., Zheng, C., Fan, Y., Zeng, C., Chen, Z., Qin, W., et al. (2014). Downregulation of MicroRNA-30 facilitates podocyte injury and is prevented by glucocorticoids. J. Am. Soc. Nephrol. 25 (1), 92-104. doi: 10.1681/ASN.2012111101

Wu, J., Liu, J., Ding, Y., Zhu, M., Lu, K., Zhou, J., et al. (2018). MiR-455-3p suppresses renal fibrosis through repression of ROCK2 expression in diabetic nephropathy. Biochem. Biophys. Res. Commun. 503 (2), 977-983. doi: 10.1016/ j.bbrc.2018.06.105

Xu, Y., Zhang, J., Fan, L., and He, X. (2018). miR-423-5p suppresses high-glucoseinduced podocyte injury by targeting Nox4. Biochem. Biophys. Res. Commun. 505 (2), 339-345. doi: 10.1016/j.bbrc.2018.09.067

Yamamura, S., Imai-Sumida, M., Tanaka, Y., and Dahiya, R. (2017). Interaction and cross-talk between non-coding RNAs. Cell Mol. Life Sci. 75 (3), 467-484. doi: $10.1007 / \mathrm{s} 00018-017-2626-6$

Yamamura, S., Imai-Sumida, M., Tanaka, Y., and Dahiya, R. (2018). Interaction and cross-talk between non-coding RNAs. Cell. Mol. Life Sci.: CMLS 75, 467484. doi: 10.1007/s00018-017-2626-6

Yang, H., Kan, Q. E., Su, Y., and Man, H. (2018a). Long non-coding RNA CASC2 improves diabetic nephropathy by inhibiting JNK pathway. Exp. Clin. Endocrinol. Diabetes efirst. 127 (8), 533-537. doi: 10.1055/a-0629-9958

Yang, Z., Guo, Z., Dong, J., Sheng, S., Wang, Y., Yu, L., et al. (2018b). miR-374a regulates inflammatory response in diabetic nephropathy by targeting MCP-1 expression. Front. Pharmacol. 9, 900. doi: 10.3389/fphar.2018.00900

Yang, S., Fei, X., Lu, Y., Xu, B., Ma, Y., and Wan, H. (2019). miRNA-214 suppresses oxidative stress in diabetic nephropathy via the ROS/Akt/mTOR signaling pathway and uncoupling protein 2. Exp. Ther. Med. 17 (5), 35303538. doi: $10.3892 /$ etm.2019.7359

Yao, T., Zha, D., Gao, P., Shui, H., and Wu, X. (2018). MiR-874 alleviates renal injury and inflammatory response in diabetic nephropathy through targeting toll-like receptor-4. J. Cell Physiol. 234 (1), 871-879. doi: 10.1002/jcp.26908

Yao, R.-W., Wang, Y., and Chen, L.-L. (2019). Cellular functions of long noncoding RNAs. Nat. Cell Biol. 21, pages542-551. doi: 10.1038/s41556-0190311-8

Yi, H., Peng, R., Zhang, L.-Y., Sun, Y., Peng, H.-M., Liu, H.-D., et al. (2017). LincRNA-Gm4419 knockdown ameliorates NF-KB/NLRP3 inflammasomemediated inflammation in diabetic nephropathy. Cell Death Dis. 8, e2583. doi: 10.1038/cddis.2016.451

Yu, F. N., Hu, M. L., Wang, X. F., Li, X. P., Zhang, B. H., Lu, X. Q., et al. (2019). Effects of microRNA-370 on mesangial cell proliferation and extracellular 
matrix accumulation by binding to canopy 1 in a rat model of diabetic nephropathy. J. Cell Physiol. 234 (5), 6898-6907. doi: 10.1002/jcp.27448

Zha, F., Bai, L., Tang, B., Li, J., Wang, Y., Zheng, P., et al. (2019). MicroRNA-503 contributes to podocyte injury via targeting E2F3 in diabetic nephropathy. J. Cell Biochem. 120 (8), 12574-12581. doi: 10.1002/jcb.28524

Zhang, Z., Peng, H., Chen, J., Chen, X., Han, F., Xu, X., et al. (2009). MicroRNA-21 protects from mesangial cell proliferation induced by diabetic nephropathy in db/db mice. FEBS Lett. 583 (12), 2009-2014. doi: 10.1016/j.febslet.2009.05.021

Zhang, Z., Luo, X., Ding, S., Chen, J., Chen, T., Chen, X., et al. (2012). MicroRNA451 regulates p38 MAPK signaling by targeting of Ywhaz and suppresses the mesangial hypertrophy in early diabetic nephropathy. FEBS Lett. 586 (1), 2026. doi: 10.1016/j.febslet.2011.07.042

Zhang, Y., Zhang, X.-O., Chen, T., Xiang, J.-F., Yin, Q.-F., Xing, Y.-H., et al. (2013). Circular intronic long noncoding RNAs. Mol. Cell 51 (6), 792-806. doi: 10.1016/j.molcel.2013.08.017

Zhang, F., Liu, H., Liu, D., Liu, Y., Li, H., Tan, X., et al. (2017). Effects of RAAS inhibitors in patients with kidney disease. Curr. Hypertens. Rep. 19 (9), 72. doi: 10.1007/s11906-017-0771-9

Zhang, Y., Zhao, S., Wu, D., Liu, X., Shi, M., Wang, Y., et al. (2018). MicroRNA-22 promotes renal tubulointerstitial fibrosis by targeting PTEN and suppressing autophagy in diabetic nephropathy. J. Diabetes Res. 2018, 4728645. doi: $10.1155 / 2018 / 4728645$

Zhang, S. Z., Qiu, X. J., Dong, S. S., Zhou, L. N., Zhu, Y., Wang, M. D., et al. (2019). MicroRNA-770-5p is involved in the development of diabetic nephropathy through regulating podocyte apoptosis by targeting TP53 regulated inhibitor of apoptosis 1. Eur. Rev. Med. Pharmacol. Sci. 23 (3), 1248-1256. doi: 10.26355/ eurrev_201902_17018

Zhou, Q., Chung, A. C. K., Huang, X. R., Dong, Y., Yu, X., and Lan, H. Y. (2014). Identification of novel long noncoding RNAs associated with TGF- $\beta /$ Smad3mediated renal inflammation and fibrosis by RNA sequencing. Am. J. Pathol. 184, 409-417. doi: 10.1016/j.ajpath.2013.10.007
Zhou, L., Xu, D. Y., Sha, W. G., Shen, L., Lu, G. Y., and Yin, X. (2015). Long noncoding MIAT mediates high glucose-induced renal tubular epithelial injury. Biochem. Biophys. Res. Commun. 468 (4), 726-732. doi: 10.1016/ j.bbrc.2015.11.023

Zhou, Z., Wan, J., Hou, X., Geng, J., Li, X., and Bai, X. (2017). MicroRNA-27a promotes podocyte injury via PPAR $\gamma$-mediated $\beta$-catenin activation in diabetic nephropathy. Cell Death Dis. 8 (3), e2658. doi: 10.1038/cddis.2017.74

Zhou, Z., Wan, J., Hou, X., Geng, J., Li, X., and Bai, X. (2018). Correction: MicroRNA-27a promotes podocyte injury via PPARgamma-mediated betacatenin activation in diabetic nephropathy. Cell Death Dis. 9 (6), 652. doi: 10.1038/s41419-018-0637-3

Zhu, X., Zhang, C., Fan, Q., Liu, X., Yang, G., Jiang, Y., et al. (2016). Inhibiting MicroRNA-503 and MicroRNA-181d with losartan ameliorates diabetic nephropathy in KKAy mice. Med. Sci. Monit. 22, 3902-3909. doi: 10.12659/ msm.900938

Zhu, F.-X., Wu, H.-L., Chen, J.-X., Han, B., and Guo, Y.-F. (2019). Dysregulation of microRNA-181b and TIMP3 is functionally involved in the pathogenesis of diabetic nephropathy. J. Cell. Physiol. 234 (10), 18963-18969. doi: 10.1002/ jсp. 28536

Conflict of Interest: The authors declare that the research was conducted in the absence of any commercial or financial relationships that could be construed as a potential conflict of interest.

Copyright $\odot 2020$ Loganathan, Sulaiman, Abdul Murad, Shah, Abdul Gafor, Jamal and Abdullah. This is an open-access article distributed under the terms of the Creative Commons Attribution License (CC BY). The use, distribution or reproduction in other forums is permitted, provided the original author(s) and the copyright owner(s) are credited and that the original publication in this journal is cited, in accordance with accepted academic practice. No use, distribution or reproduction is permitted which does not comply with these terms. 